\title{
THE INFLUENCE OF GREEK PHILOSOPHY ON ISLAMIC CULTURE AL-TAWHIDI IS A MODEL
}

\author{
Nada Mousa ABBAS ${ }^{1}$
}

\section{Istanbul / Türkiye \\ p. $528-542$}

\section{Received: 02/12/2021 \\ Accepted: $16 / 12 / 2021$ \\ Published: 01/01/2022}

This article has been scanned I iThenticat No plagiarism detected

\begin{abstract}
:
The East, with its ontological history, is full of religions, and the spirituality of the eastern mind is evident in its love for the literature of proverbs and wisdom that it was able to formulate, and its sanctification of the word is only due to its magical impact on himself; It is his consolation for his painful reality! It deals with its concepts and religious and worldly matters, and that he did not digest Greek philosophy until after the writers presented it with short sentences with wise meanings from the sayings of its philosophers! It is known that wisdom and proverbs are advice, guidance, advice and exhortation, expressing a subjective experience, length of contemplation and insight into life matters, and they often have moral dimensions and that they are suitable for all human societies in a time and place.

The concept of culture is so complex that it includes all human aspects. Speaking about the impact of Greek culture on Arab culture or even the presence of multiple connections, it stems from the phenomenon of influence and influence. Greek philosophy was mixed with Islamic thought and culture in the Abbasid era in general, and Arabic literature in general. In particular, it became one of the tools of expression, and the Greek philosophical culture penetrated into the Arab culture (its terms, concepts and sayings of its philosophers) until it spread in its three types: pure philosophical culture, literary philosophy, and philosophical literature. Islamic Society As the names of Greek philosophers gained popularity among members of society in all its classes!

The research focused on the issue of the impact of Muslim writers on the dissemination of Greek philosophical culture in the Abbasid era, taking from Abu Hayyan al-Tawhidi (d. 414 AH / $1023 \mathrm{AD}$ ) as a model; Although al-Tawhidi was not unique in mixing literature with philosophy; But it is a typical example of the writers of the Abbasid era who were influenced by Greek philosophy and whose literary culture was mixed with Greek philosophy. Greek philosophy has spread among members of the Islamic community by publishing the wisdom, proverbs and sayings of Greek philosophers and scientists.

The research was divided into three sections that dealt with the first topic: the relationship between literature and philosophy,
\end{abstract}

http://dx.doi.org/10.47832/2717-8293.15.37

1 iD Dr. , Diyala University, Iraq, nadaal.mosawi@yahoo.com 
while the second topic: the reasons for monotheistic influence on Greek philosophy, and the third topic: it follows the impact of Greek philosophy with the works of monotheism.

Key words: Culture, Philosophy, Literature.

\section{تأثير الفلسفة اليونانية في الثقافة الإسلامية}

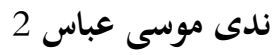

الملخص:

الشرق بتاريخه الأنطولوجي حافل بالأديان، وروحانية العقل الشرقي ظاهرة في حبه لأدب الأمثال والحكم التي جبل على صياغتها، وما تقديسه للكلمة إلا لوقعها السحري في نفسه، فهي عزاؤه عن أليم واقعه! يعابج بها مفاهيمه

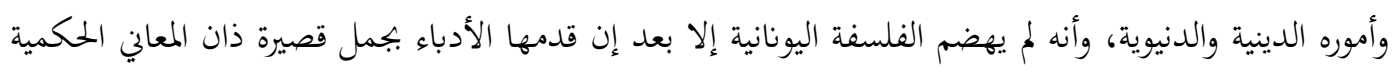
من أقوال فلاسفتها! والمعروف إن الحكم والأمثال هي نصح وإرشاد ونصح وموعظة، تعبر عن بتربة ذاتية وطول

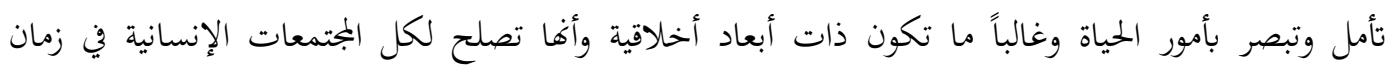

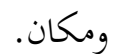
ركز البحث على مسألة أثر الأدباء المسلمين في نشر الثقافة الفلسفية اليونانية في العصر العباسي متخذاً من أبو

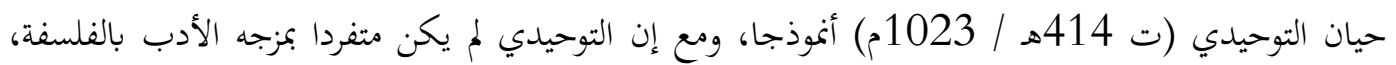

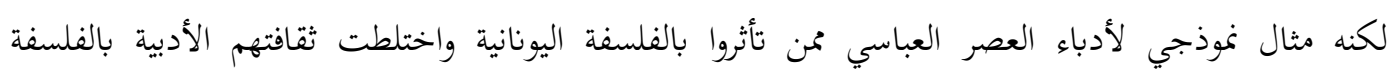

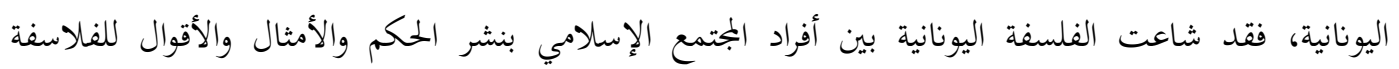
والعلماء اليونانيين. الكلمات المفتاحية: تاريخ، فلسفة، التوحيدي.

الشرق بتاريخه الأنطولوجي حافل بالأديان، وروحانية العقل الشرقي ظاهرة في حبه لأدب الأمثال والحكم التي جبل على

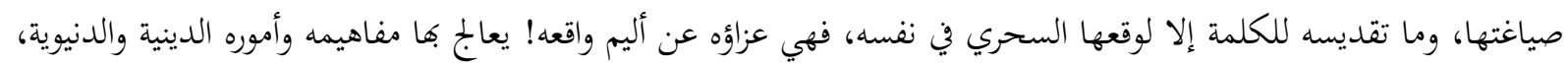

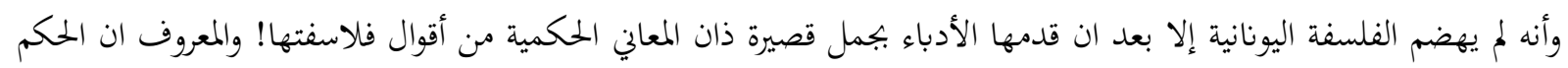

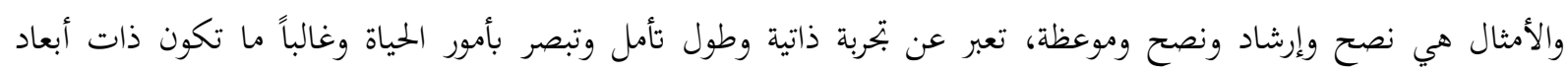

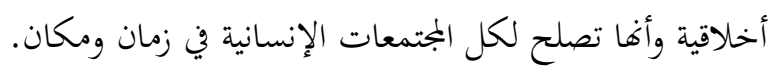

إن مفهوم الثقافة من التعقيد يصل لدرجة انه يشمل جميع النواحي الإنسانية، وفي الحديث عن أثر الثقافة اليونانية في

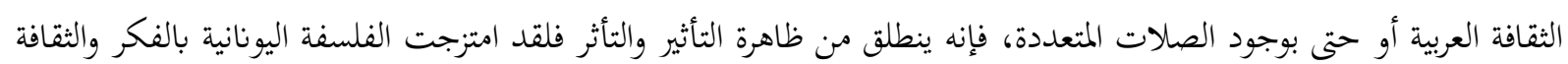

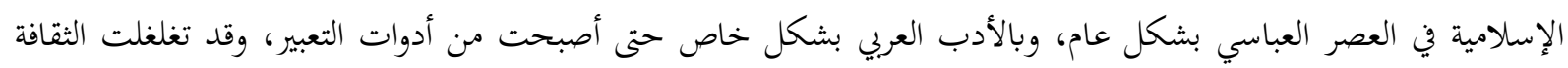

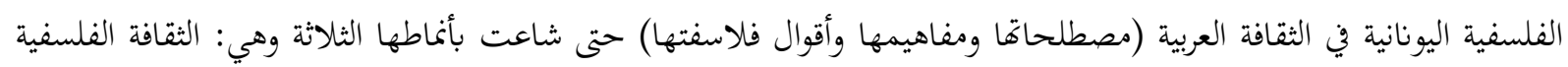


البحتة، الفلسفة الأدبية، والأدب الفلسفي ولذذا فقد ظهرت في نتاجاتما هوم ومشاكل فلسفية وإنسانية معبرة عن واقع البيئة في

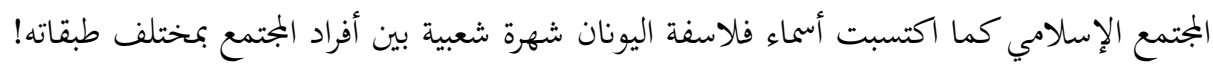
ركز البحث على مسألة أثر الأدباء المسلمين في نشر الثقافة الفلسفية اليونانية في العصر العباسي متخذاً من أبو حيان

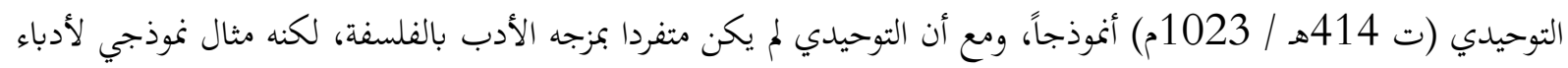

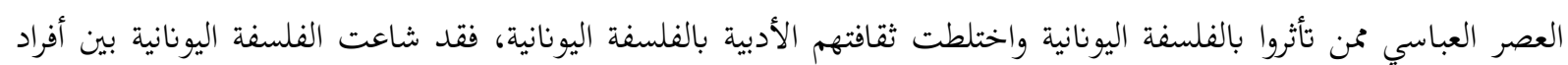
المجتمع الإسلامي بنشر الحكم والأمثال والأقوال للفلاسفة والعلماء اليونانيين. يبدو تأثر التوحيدي بالفلسفة اليونانية واضحاً بما أقتبسه من أقوال قصيرة حملت طابع الحكمة وبثها بين دفات كتبه لأشهر وأبرز وأهم الفلاسفة اليونانيين (الإغريق)، وكان قصده من تطعيم نتاجاته الأدبية وثقافته الإسلامية المحلية بثقافة الفلسفة اليونانية هو لتطويع المعنى وتعميقه للقارئ بشكل محسوس و تأكيده على المعلومة النافعة وتقريب فهم المعاني والقضايا والمسائل

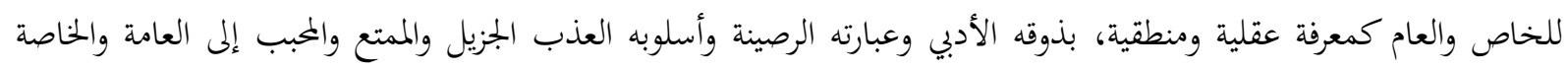
وبالسهل الممتنع.

لقد عكست مقتبسات التوحيدي للأقوال الفلسفية اليونانية، عقليته الفكرية الأرستقراطية المتفتحة للعلوم والمعارف والفلسفة وكل ما يخص طبقة العلماء والفلاسفة والمفكرين، ودرايته بثقافة عصره، فوبدا شغوفاً بالحكمة والمنطق والفكر والأقوال

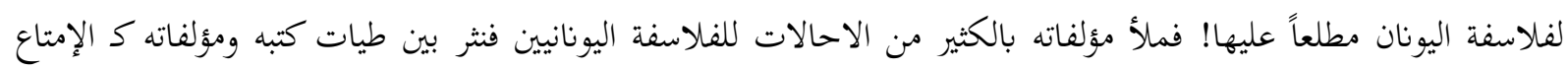
والمؤانسة والبصائر والذخائر والهوامل والشوامل والمقابسات والصداقة والصديق مقتبسات متنوعة من الترات التهات الأدبي العربي وأقوال

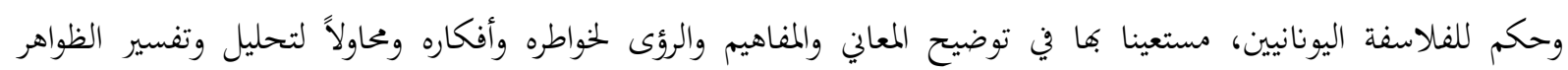
والحالات التي يشخصها في بجتمعه وبيئه.

تعتبر كتابات التوحيدي مؤلفات لا نظير لها من بين الكتب الباقية من التراث الإسلامي الوسيط كما أن أسلوبها البالغ

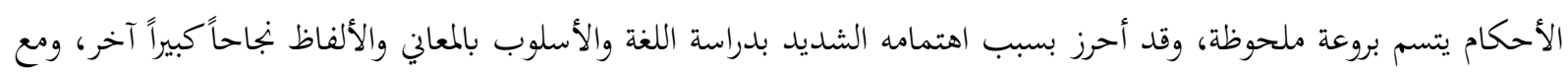

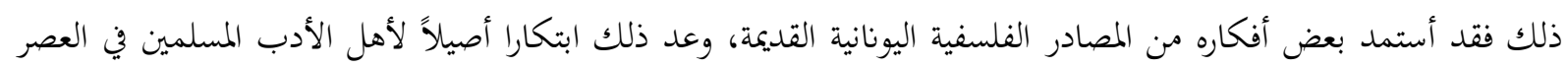
العباسي بالدرجة الأولى وبشكل ملحوظ. قسم البحث إلى ثلاثة مباحث تناول المبحث الاول: العلاقة بين الأدب والفلسفة، فيما بين المبحث الثاني: أسباب تأثر

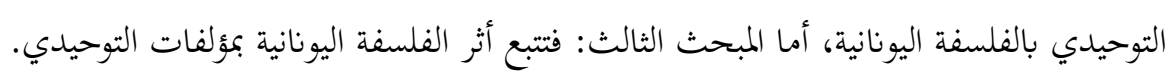

\section{أولاً: العلاقة بين الأدب والفلسفة:}

من الطبيعي أن نتساءل هنا هل تأدب الإنسان فبحث عن المعاني والأفكار لتنشأ منها الفلسفة؟! أم أنه تفكر وتفلسف

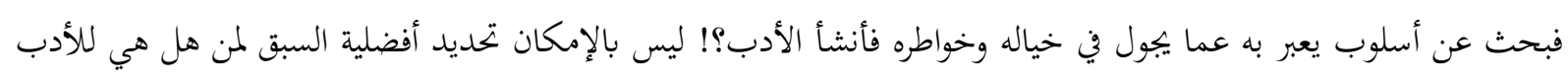

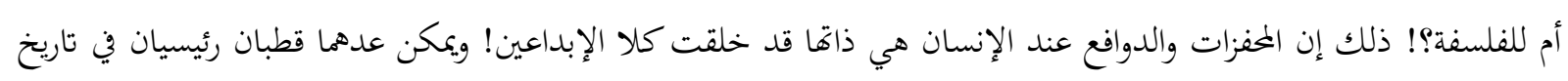

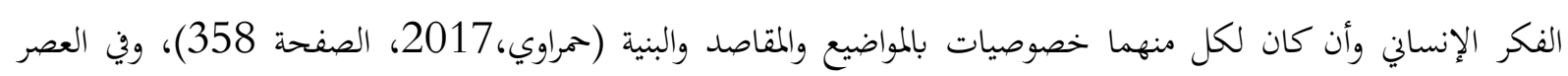
العباسي بدا لنا الأدب وقد حمل بين جنباته هوم وقضايا إنسانية برؤى ونظرات فلسفية! تعد اللغة القاسم المشترك الأول والأهم بين الأدب والفلسفة! أما القاسم المشترك الثاني بينهما فهو استخراج الأفكار

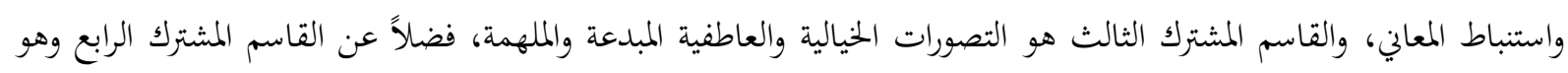

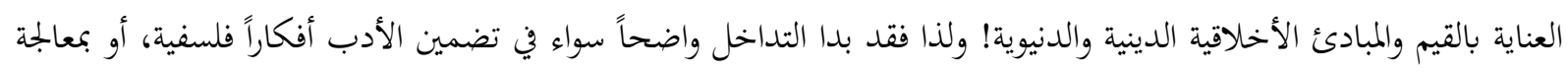


قضايا فلسفية بأسلوب أدبي جميل واضح وسلس وأيضا جميل ومبدع! يشد الإحساس إليه قبل الفهم، ومما هو مؤكد ان العديد من

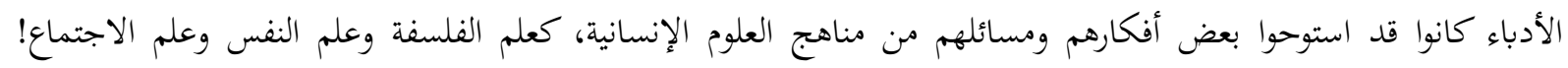

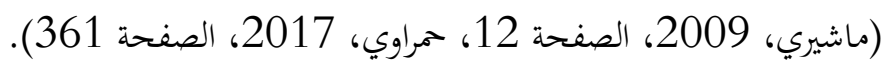

إن التمازج بين الأدب والفلسفة لا يعني ذوبان الحدود بينهما أو تلاشيها! فالاختلاف بينهما قائم ف العملية الأدبية تتميز

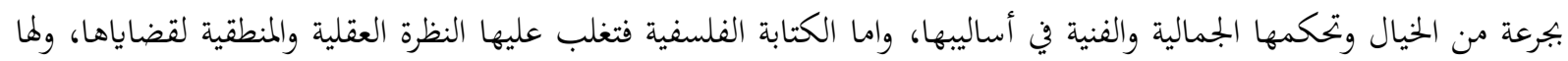

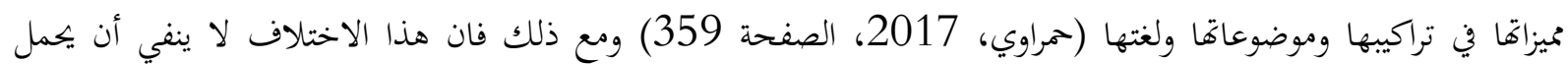

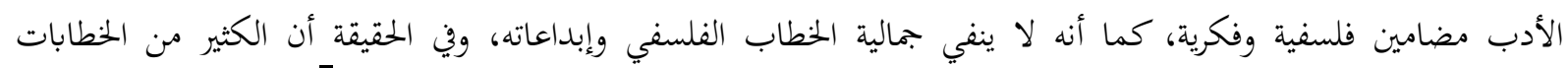
الفلسفية القديمة والحديثة عرفت تسلل جماليات التعبير الأدبي في ثناياها، بل كانت تعبّر عن أعمق القضايا الفلسفية في قالب أبلى أدبي (حمراوي، 2017، الصفحة 361).

لقد حمل العديد من الفلاسفة وعلى مر العصور هموم الإنسانية سواء كانت علمية أم أدبية! وعلى الرغم من لغتهم الصارمة

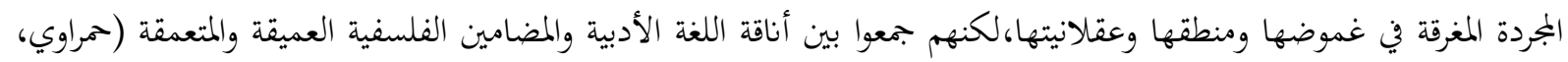

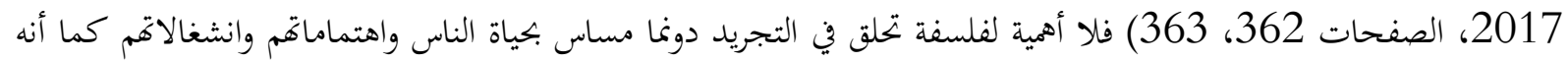
لا أهمية لأدب في أي جنس أدبي كان، إذا خلا من المعنى، إذ المعنى هو الذي يبث الحياة وأسباب بقائها واستدامتها في الأعمال

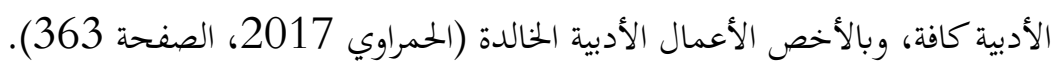

ولدينا على سبيل المثال جمهورية أفلاطون، فأننا نلاحظ إن أفلاطون قد أستوعب كل المموم والمشاكل والأفكار بفلسفته المتعمقة وصاغ حواراته بأسلوب أدبي، زاد في توهج ورُقي نتاجه الفكري، اذ حوى نسقه الفلسفي مجالات معان معرفية عدة من الحياة

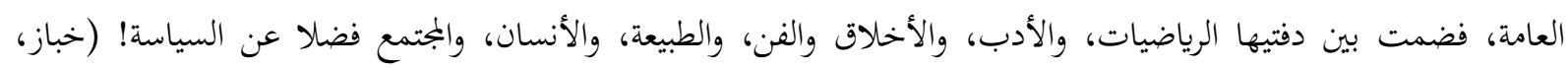
جمهورية أفلاطون، 1983).

والأمثلة التي تثبت أن كل أدب حقيقي هو في حاجة هذا القدر أو ذاك إلى الفلسفة (الزكوي، 2017)، مثل قصة الفيلسوف أبن طفيل المعنونة بـ حي بن يقظان وهي قصة فلسفية( الزكوي، 2017)، فكل الآداب العظيمة التي تمكنت من البقاء

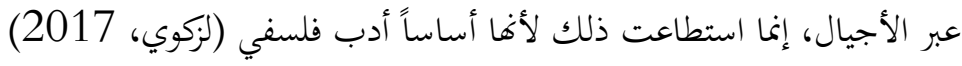

ويرى زكريا إبراهيم إن الباحثين قد أهتموا بطائفة الفلاسفة وطائفة الأدباء، ولكنهم لم يهتموا بطائفة الأدباء الفلاسفة أو

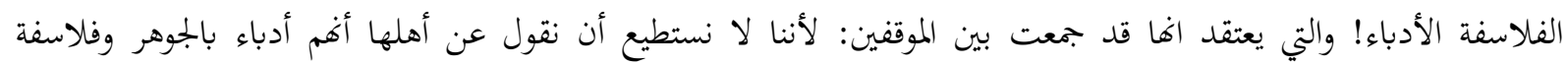

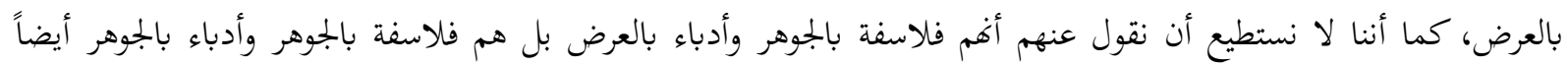
(إبراهيم، الصفحة 3). (3).

من المعروف ان الأقوال والأمثال التي تدخل في مجال الحكمة تعد إرهاصات للتفكير الفلسفي ونظراً لطبيعتها الإنسانية

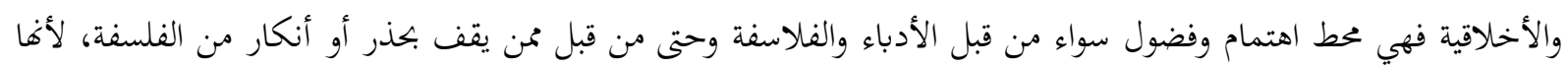

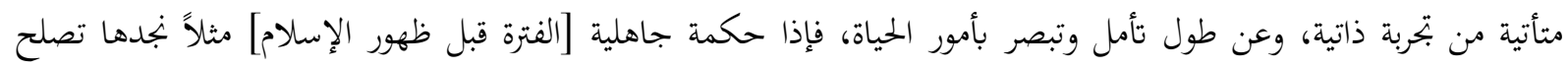

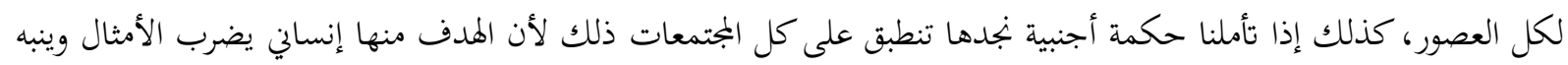

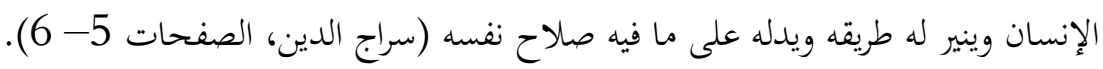
لم يكن ان التوحيدي متفرداً هذا الاتحاه، فقد سبقه عدد من أدباء القرنين الثالث والرابع الهجريين التاسع والعاشر

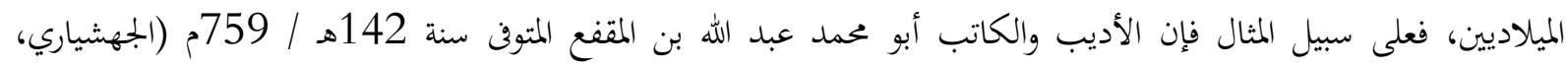

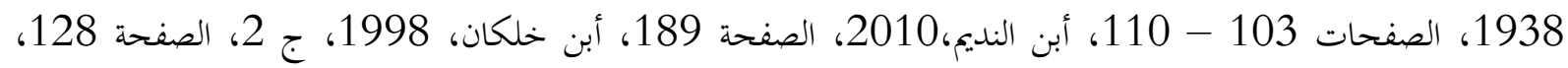


الشريف المرتضى، 1429هـ، ج 1، الصفحات 151 - 153) يعد من أول الأدباء الذين دبجوا الثقافة الفلسفية اليونانية

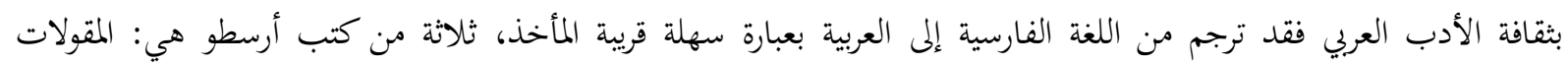

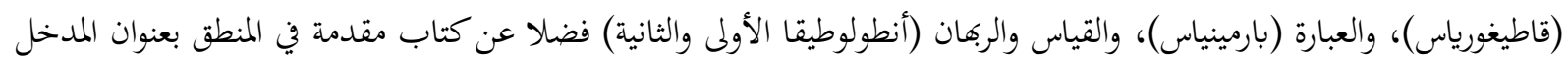

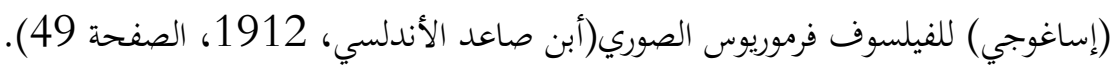

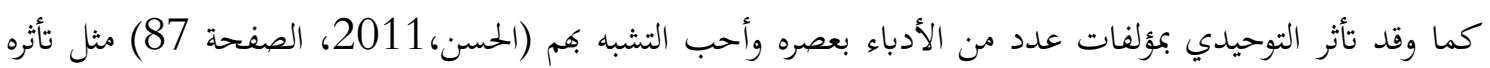
بالأديب الكبير الجاحظ المتوف سنة 255 هـ/ 868 م، الذي فاقت شهرته على كل أديب مفوه سبقه ولحقه في عصره والعصور

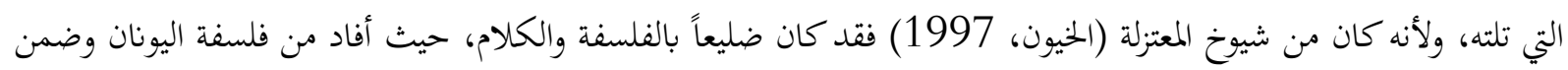
معارفه منها في شتى مسائله ورسائله المتنوعة التي حوتا مؤلفاته الأدبية والتاريخية والاجتماعية والأخلاقية والعقلية والعلمية (بلات، 1961، 1961، الدهماني، 2021).

وصاحب كتاب المعارف أبو حنيفة الدينوري المتوف سنة 276هـ / 889 م، والذي وصفه التوحيدي في كتابه المفقود

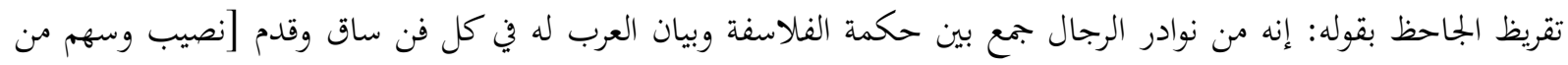

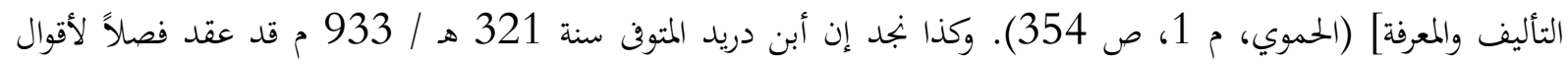

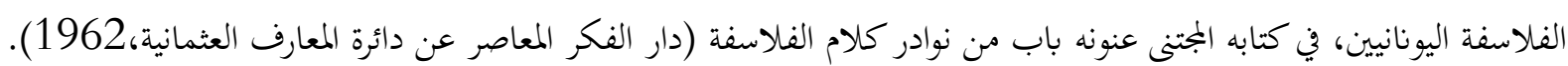
أما الفيلسوف والعالم والأديب والفقيه والجغرافي أبي زيد البلخي المتوفن سنة 322هـ / 934م، فقد لقبه الحموي بجاحظ

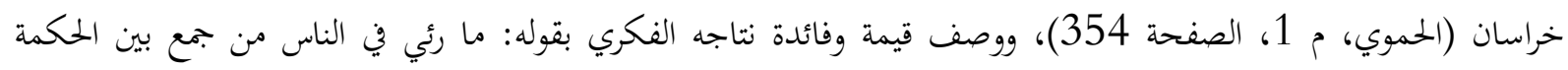

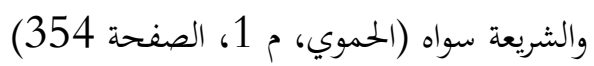
لقد ترك أبي زيد البلخي نتاجاً علميا وفلسفياً غزيراً، وصل إلى ما يربو السبعين (70) مؤلفاً بسائر علوم عصره

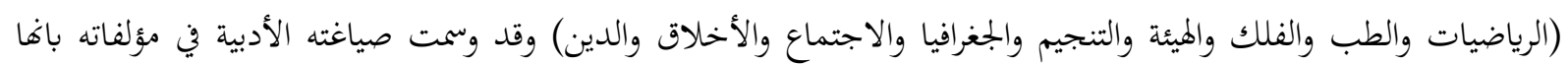

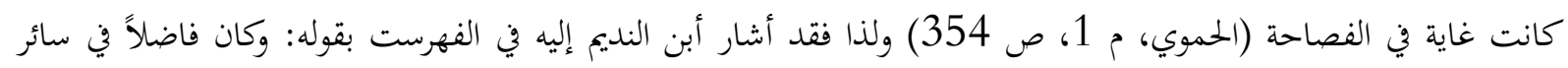

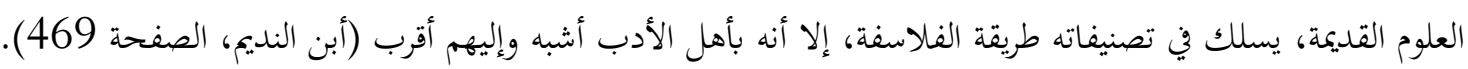
ويظهر تأثير الفلسفة اليونانية واضحا عند الكاتب الديواني قدامة بن جعفر المتوفى على الأرجح سنة 337 3ـ / ذكره أبن النديم قائلاً: كان قدامة أحد البلغاء الفصحاء والفلاسفة الفضلاء ممن يشار إليه في علم المنطق (أبن النديم، الصفحة

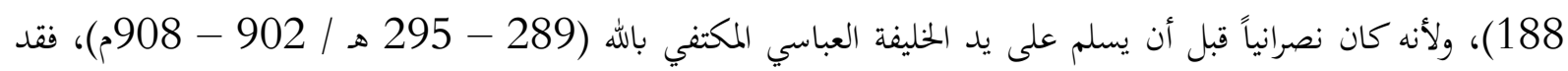

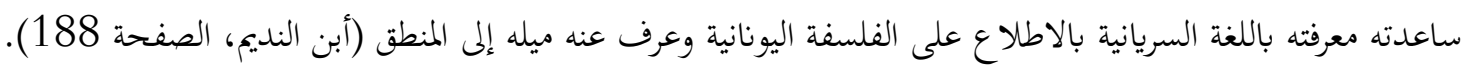
وبالمقابل فقد تأثر عدد من الأدباء بالتوحيدي فنقلوا عنه أقوال لفلاسفة أو علماء يونانيين، وأصبح نقل الأقوال عن

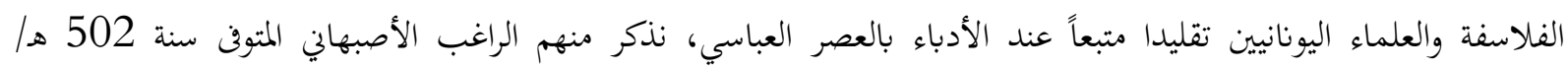

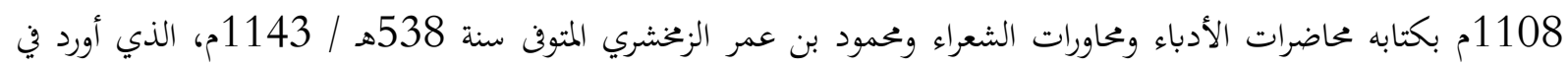

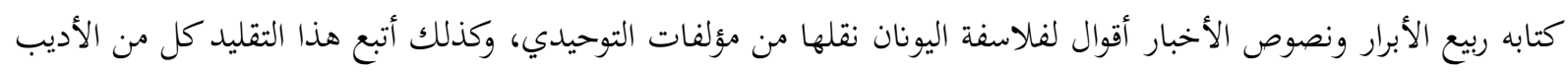

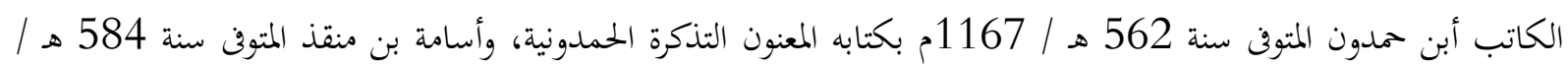

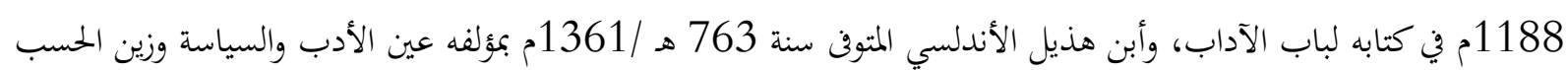


لقد ظهر انفتاح العقل العربي بشكل جلي على كل ألوان الثقافات العالمية، لعدم تعصبهم أو تزمتهم وفي التراث الثقافي

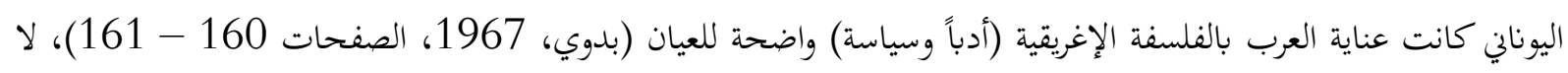

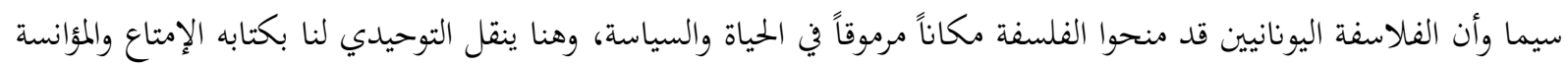
رأي عن الفيلسوف ديوجانيس في الفلسفة عندما سُئل: متى تطيب الدنيا؟! فكان رده: إذا تفلسف ملوكها وملك فيك فلاسفتها (التوحيدي، 2007، الصفحة 222).

من الواضح جدا ان التوحيدي لم يكن يتعامل مع الفلسفة اليونانية بأها ترفاً ثقافياً، بقدر ما هيه وسيلة وأداة تساهم في

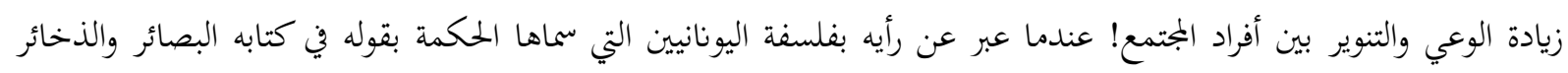

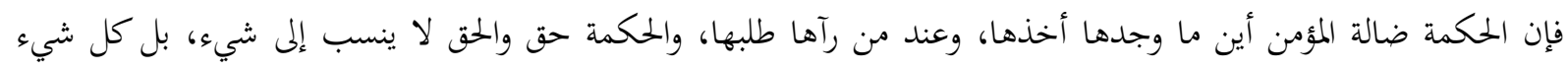

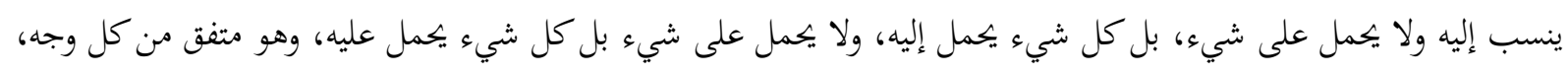

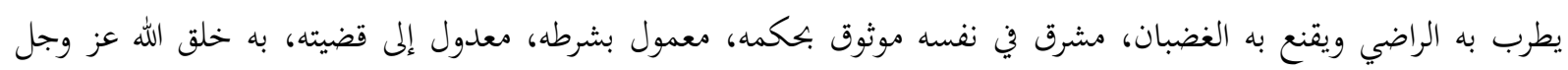

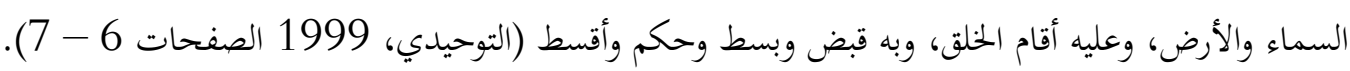
إن من أهم ما تميزت به الحضارة الإسلامية هو التسامح وذلك ما أشار إليه المستشرق آدم متز بقوله: لم يكن معروفاً في

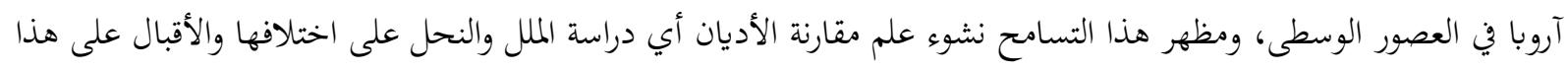

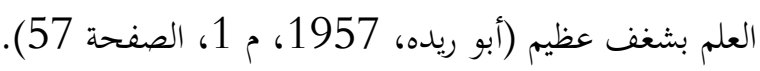
ولا ريب إن القيم الإنسانية النبيلة التي زهت بها أقوال فلاسفة اليونان كانت من أهم الأسباب التي جذبت التوحيدي

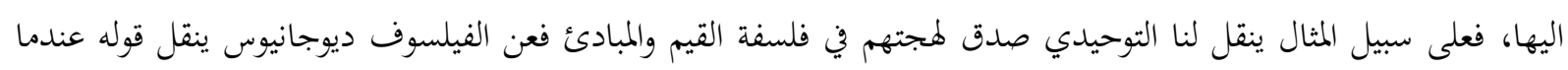

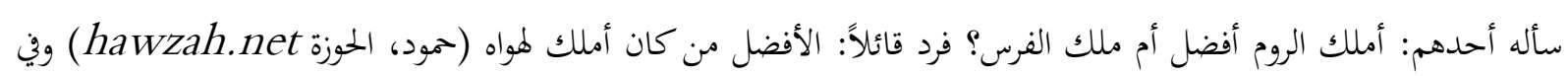

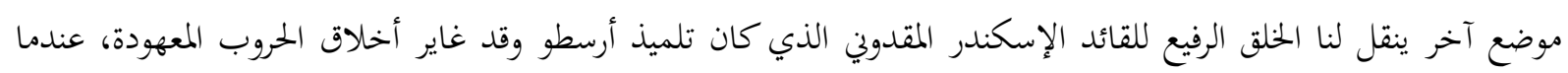

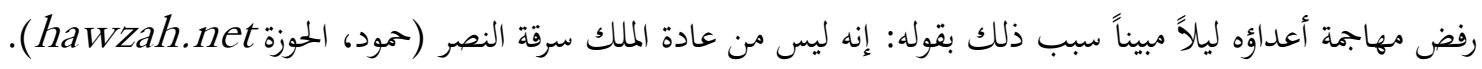
وكذلك هناك تأثير آخر على الثقافة العربية وهي في تأثير الحاكم على الرعية، نظراً لأن الناس على دين ملوكهم، والرواية

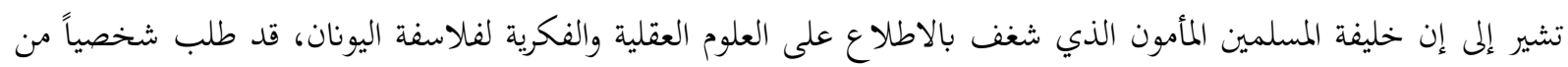

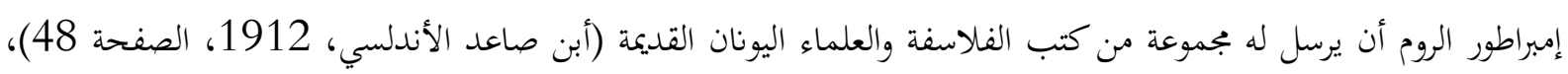
ولا شك ان اهتمام الخليفة هذا أثر على أذواق الرعية لأن الفضول دفعهم للاطلاع على التراث الفلسفي والعلمي والفكري لهؤلاء الفلاسفة والعلماء.

وصف ياقوت الحموي المتوف سنة 626هـ/ 1228م التوحيدي بمقولة أشتهر بها على مر الزمان! عندما قال عنه إنه فيلسوف الأدباء وأديب الفلاسفة (الحموي، مجلد 4، الصفحة 288) فقد كان التوحيدي موسوعي يعنى بالمعاني والأفكار والتساؤلات ذات المغزى الفلسفي أدت إلى نشوء علاقة وثيقة لديه بالفكر والقضايا الفلسفية اليونانية، فهو فيلسوف السؤي المال

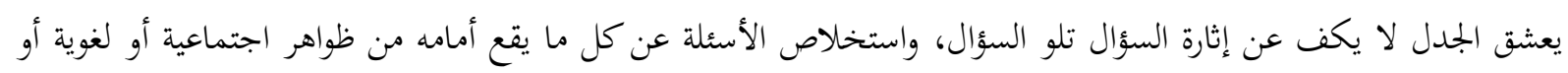

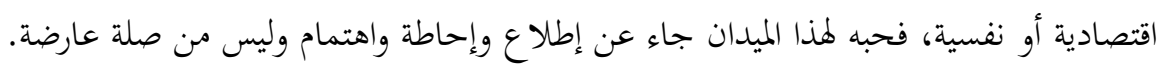

أبته التوحيدي نحو الثقافة الفلسفية اليونانية التي أعطته زاداً منوعاً أضافه إلى خزينه المعريف اذ طعم كتاباته الأدبية بأقوال

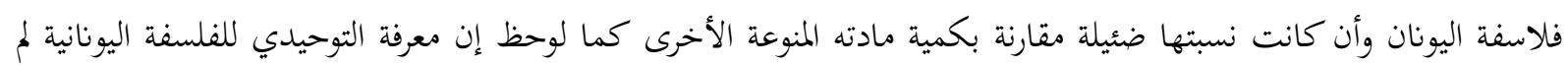

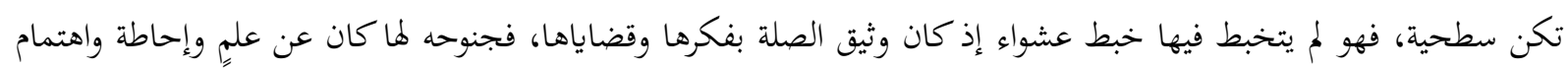


وحبه العقلاني للفلسفة كان وجودياً كأديب وإنسان، ويبدو أنه وجد فيها ملاذاً للتعبير عما يخالج فكره وما يعتمل في نفسه وما يعاني منه في حياته، مجارياً فيها روحية عصره.

كان التوحيدي أديباً يعبر بإحساسه عن المعاني، ثم يعود ليكسبها مسحة عقلية، ويمنحها نظرة فلسفية، وقد كان تأثره بالفلسفة اليونانية أمر ملحوظاً طغى على كل مؤلفاته، الأمر الذي يكشف النف تعاطيه للفلسفة اليونانية وموسوعية معارفه وشموليتها،

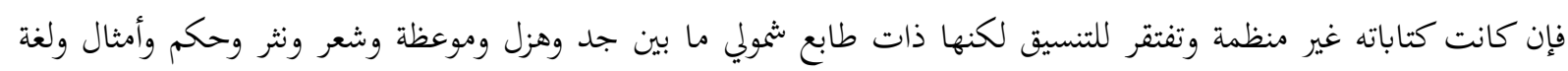

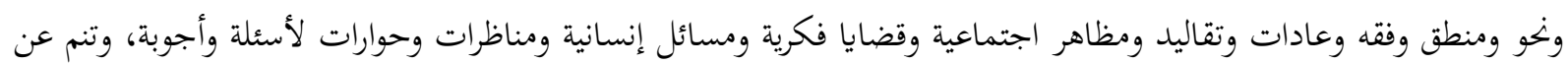

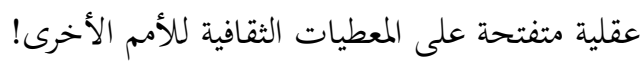
وعندما وضع التوحيدي يده على مواطن النفع في الفلسفة اليونانية، كان مثالا للأمانة في النقل هذا من جهة، ومن جهة

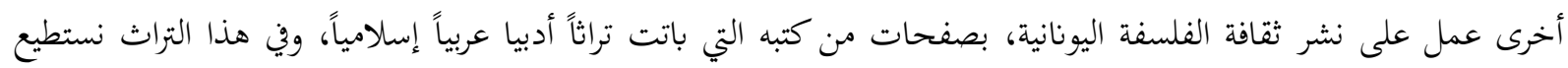

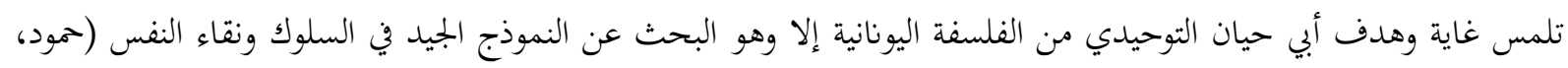

الحوزة hawzah.net)

عند تتبع ما أورده التوحيدي من أقوال الفلاسفة اليونانيين لاسيما في مؤلفاته الثلاثة الإمتاع والمؤانسة والبصائر والذخائر

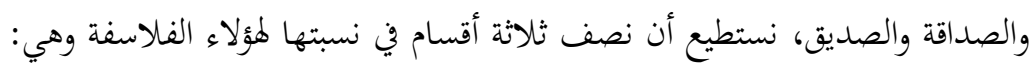
1- مشاهير فلاسفة اليونان وعلماؤها، الذين كانوا من أعلام الفلسفة اليونانية المعروفين عند الكتاب والعلماء والفلاسفة

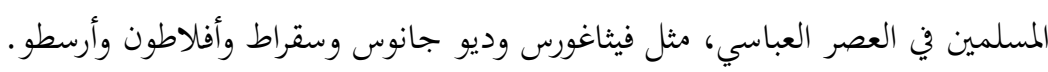

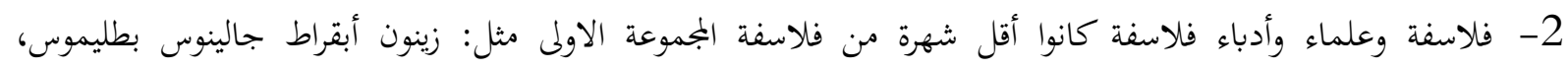

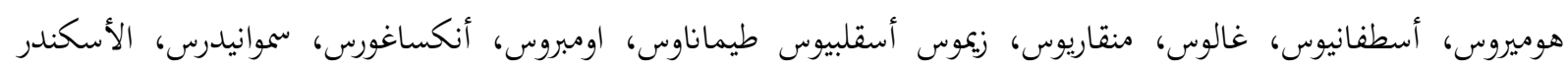
المقدوني.

3- فلاسفة لم يشر التوحيدي لأسمائهم وهم أكثر بالعدد من المجموعتين الأولى والثانية وأكتفى بنعتهم بالفلاسفة!

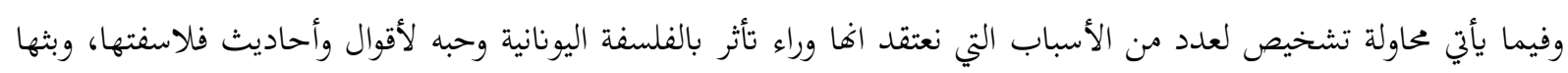

كل البشر يسعون وراء السعادة! والتوحيدي واحد منهم فقد عاث حياته برمتها يبحث عن السعادة التي حرم منها ولم

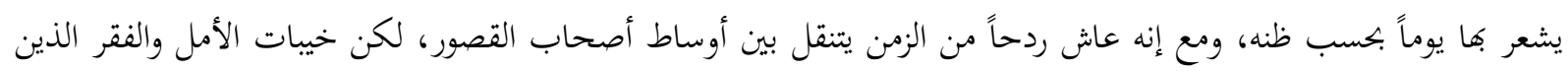

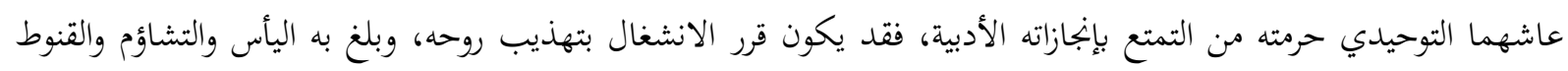

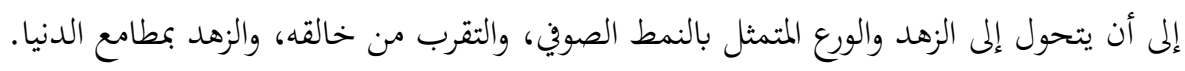

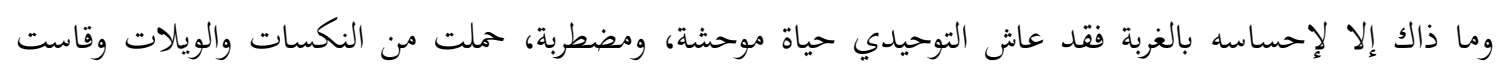

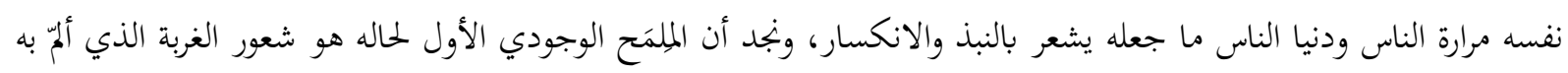

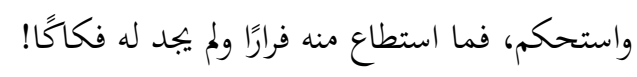

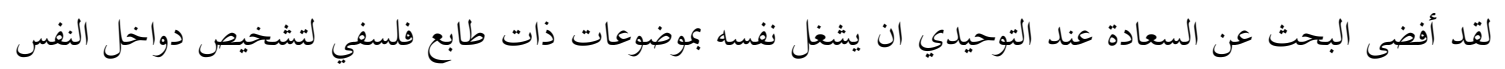

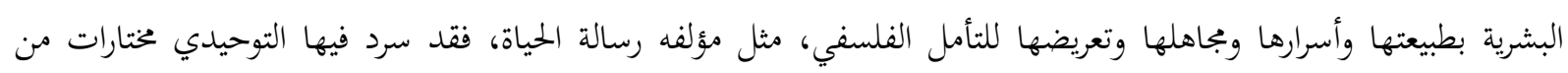

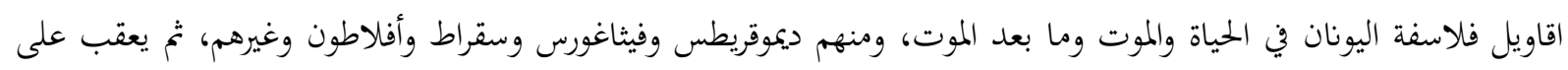


كلامهم بتعليقات مقتبسة من أبي سليمان المنطقي، وأبي زكريا الصيمري وعيسى بن زرعة وأبي الخير الخمار وغيرهم (ابراهيم، الصفحة 125).

قدم التوحيدي لنا في كتابه أخلاق الوزيرين الصاحب بن عباد وأبن العميد صورة مشرقة لفلاسفة اليونان وكيف كان

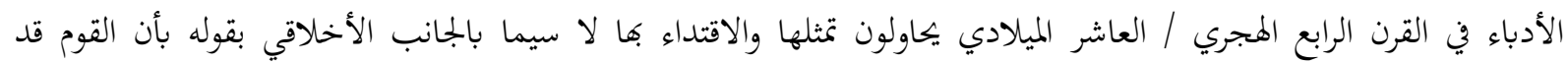

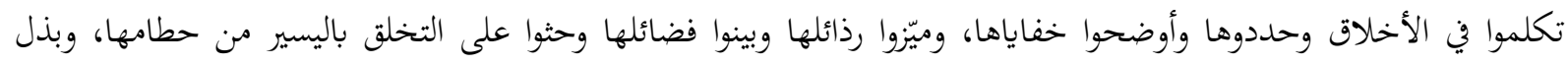

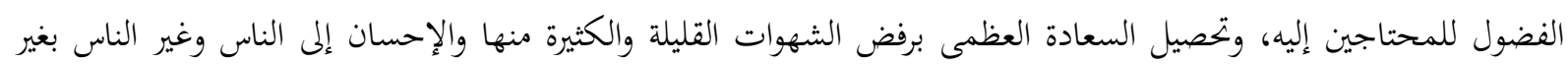

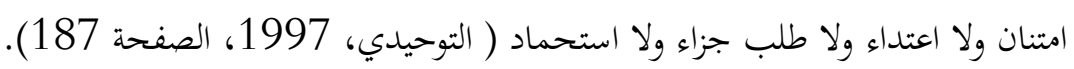

وما فتأ التوحيدي يذكر شدة تأكيد الفلاسفة اليونانيين على مسألة الأخلاق، ويدعو لمن أطلع على فلسفتهم وأحبها ان

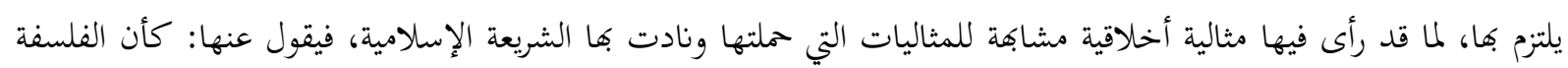

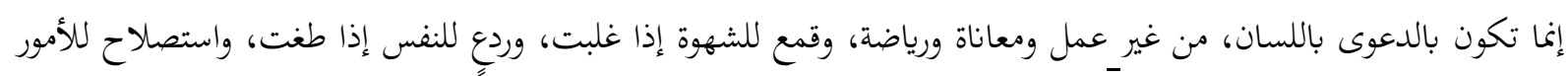

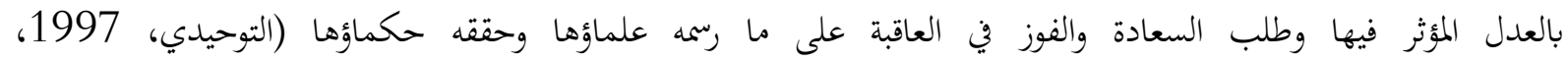

الصفحة237).

ولذا نجد التوحيدي على سبيل المثال ينتقد ويذم وزير ركن الدولة البويهي (320 - 366هـ / 932 - 976م) الكاتب أبن العميد المتوف على الأرجح سنة 366هـ / 987م، والذي لقب بالجاحظ الثاني فرغم توسع معرفة أبن العميد بالفلسفة

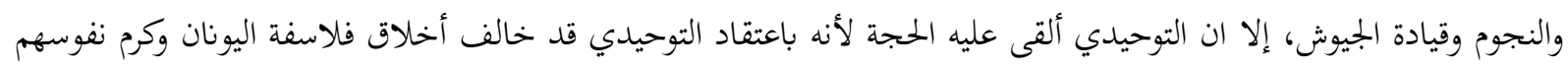

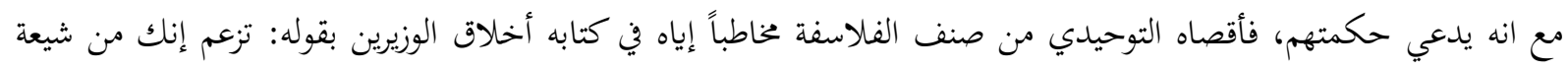

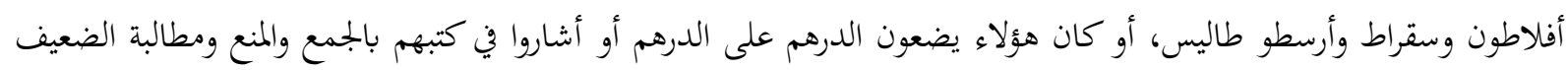

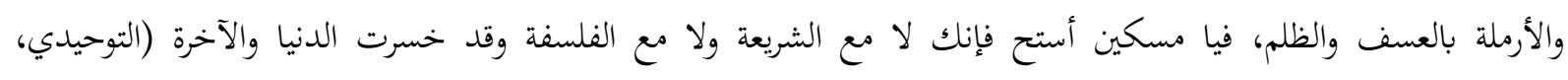
1997، الصفحة 166).

لقد أظهر التوحيدي إعجابه وشغفه بالفلسفة وأقوال ومسائل الفلاسفة والعلماء اليونانيين فكان يدافع عن فجهم الأخلاقي والعقلاني بالالتزام به، فعلى سبيل المثال قد ذم أبن زُرعة الذي كان هو الذانئ الآخر معجباً بالثقافة اليونانية، فذكر يوماً

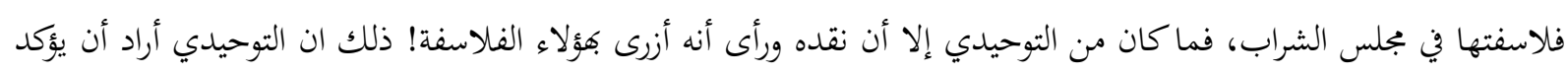

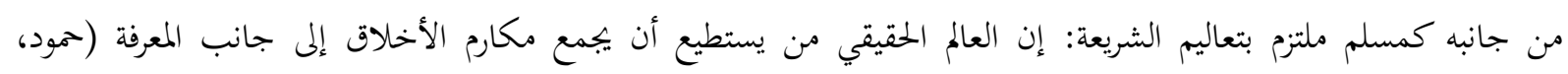
الحوزئ.nawzah. (haw

إذن لا نستبعد أن يكون التوحيدي قد وجد في الفلسفة اليونانية متنفساً نفسياً وأخلاقيا يخفف عنه ما كان يعانيه من

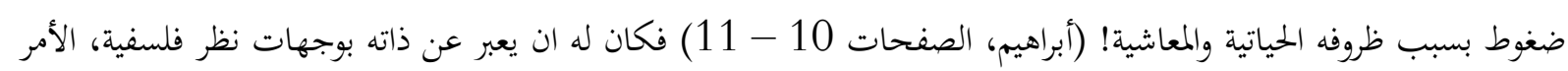

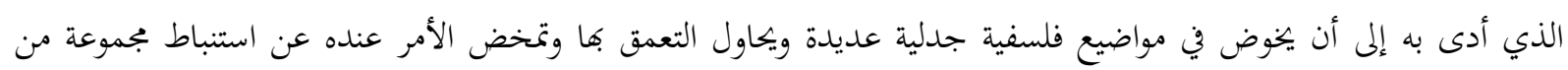

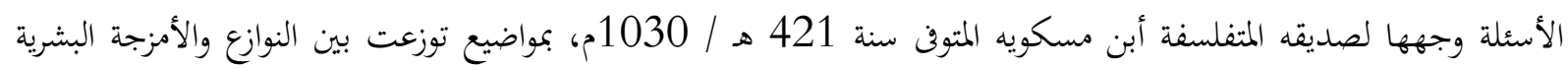

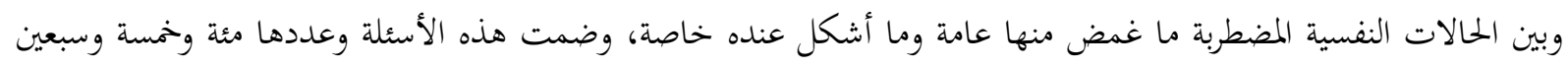

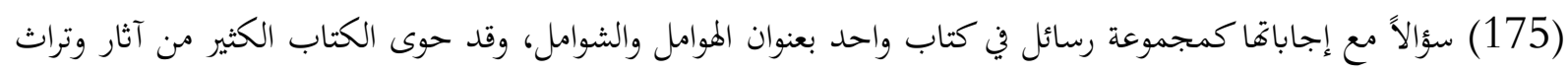

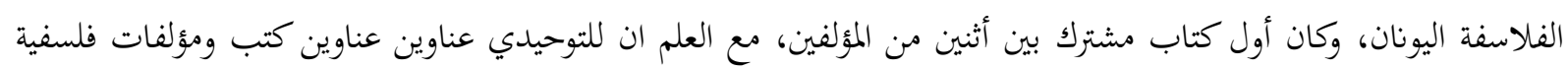
نذكر منها: المقابسات، كتاب الاقناع، الإشارات الإلهية المحاضرات والمناظرات الحج العقلي اذا ضاق الفضاء عن الحسن الفين الشرعي، 
رياض العارفين، رسالة في ضلالات الفقهاء في المناظرة رسالة في أخبار الصوفية، التذكرة التوحيدية، رسالة الحياة رسالة بيان ثمرات العلوم، رسالة الامامة أو رواية السقيفة.

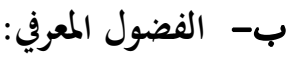

كانت الفلسفة اليونانية عند التوحيدي طريقاً للبحث عن الحقيقة الموضوعية في الحياة، فلا نستبعد نظراً لذهنيته المتفتحة

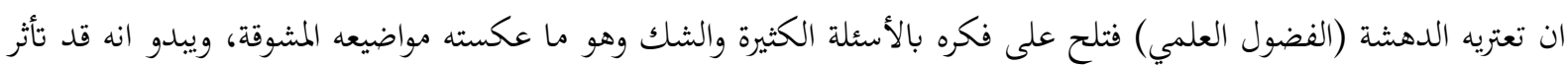

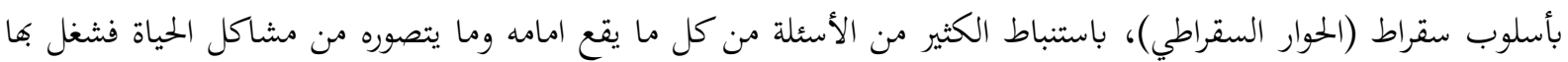

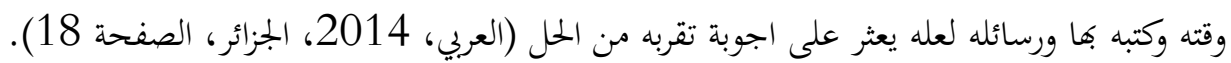

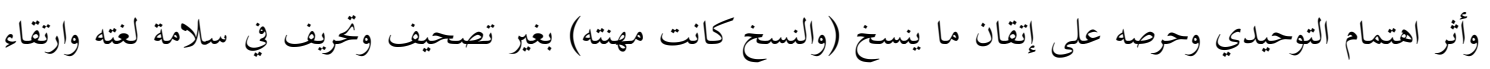

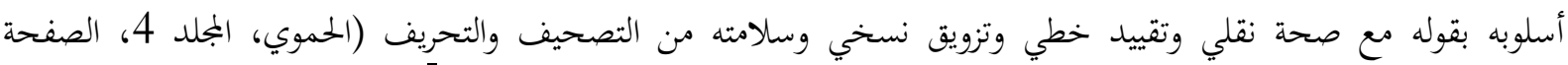

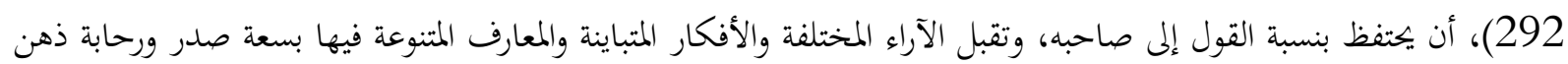

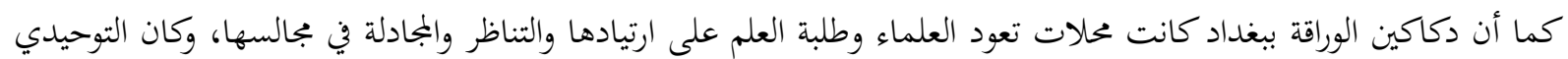
يشهد هذه المناظرات ويدونها.

ولهذا نلاحظ الموسوعية والتنوع والتلون بالمعارف لدى الأدباء فضلاً عن العلماء، فعلى سبيل المثال حوى كتاب التوحيدي البصائر والذخائر من المعارف الأدبية والنوادر والفكاهة والتاريخ والتصوف، فضلاً عن الكثير من الأحاديث العلمية والمسائل والأقوال من الفلسفة اليونانية جمعها التوحيدي وحشدها على مدى خمسة عشر (15) سنة مما سمع وقرأ. وقد عكس كل ذلك ذلك ولك بقوله يصف كتابه البصائر والذخائر قائلاً: حوى من الذهن لواقحه، ومن العقل قرائحه ومن الأخلاق محاسنها، ومن العلم

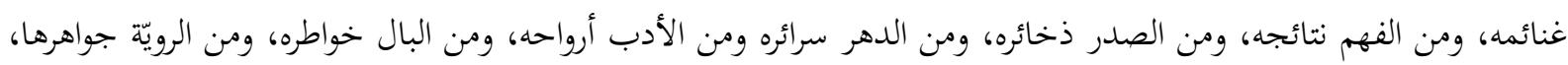

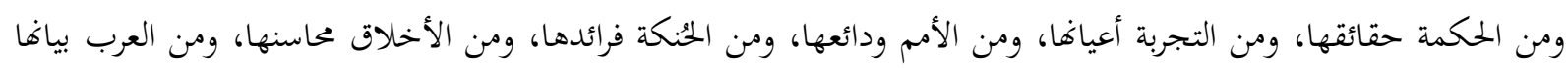

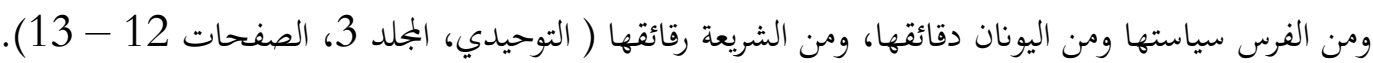
ولذلك فإن القيمة العلمية والمعرفية لمذا الكتاب البصائر والذخائر عديدة يحصيها التوحيدي بقوله: فهو أذن للكليل

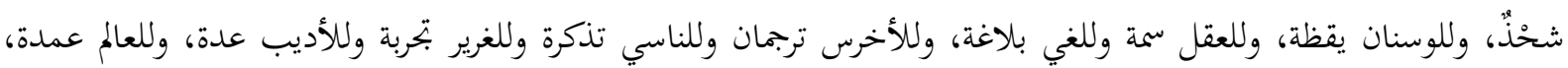
وللخامل نباهة وللناسك بصيرة وللعاقل نصيحة جمعتُ فيه كل غرة لائحة، وحجة واضحة، وبرهان مبين، وقول متين، ونادرة

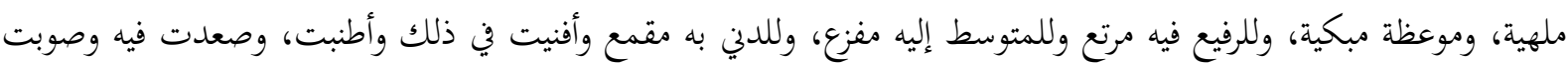

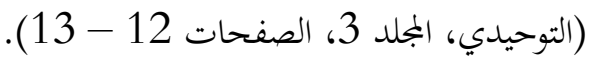

ورغم سوء الطالع وكثرة التشكي اللذين وسما حياة التوحيدي، إلا انه أتصف بالنباهة والتدقيق ورجاحة العقل التي كانت

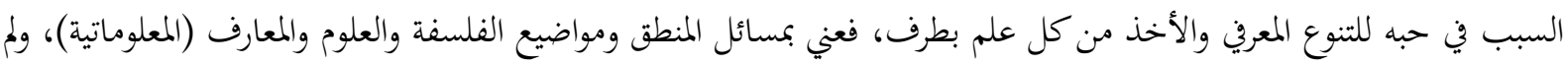

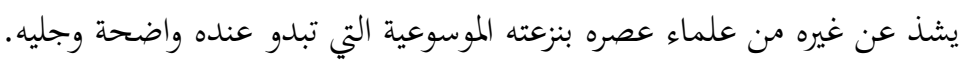

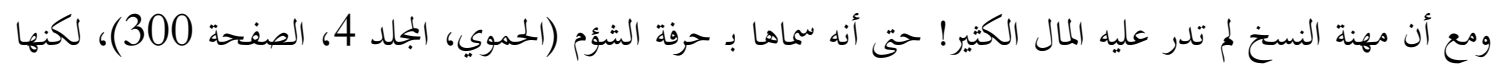
أفادته في التطبع بعدة أمور منها: 1 - مبعته على تقبل الآراء المختلفة والأفكار المتباينة. 2- أنعكس اهتمامه وحرصه على أتقان النسخ بغير تصحيف ولا تحريف، على خاصيته في الحفاظ على نسبة الأقوال لأصحابها والدقة في إيرادها. 3- ساعدته على التفرغ للفلسفة والتمعن في أقوال الفلاسفة اليونانيين، وبيان سلوكياتم ومدى التزامهم بثوابهم الأخلاقية. 
من الواضح ان الأديب العربي في العصر العباسي، قد ألغى كل الفوارق العرقية والدينية وأنفتح على ثقافات كل الشعوب،

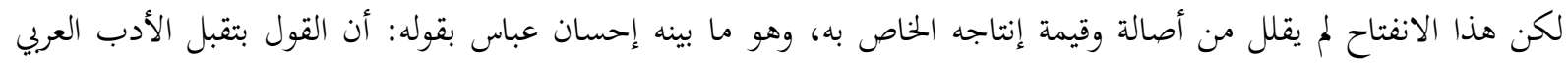

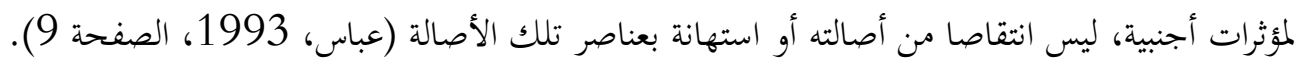
لقد سادت بيئة التوحيدي التيارات العقلية والفكرية والبحث والجدال، تلك الاجواء التي رافقت فلاسفة العصر العباسي،

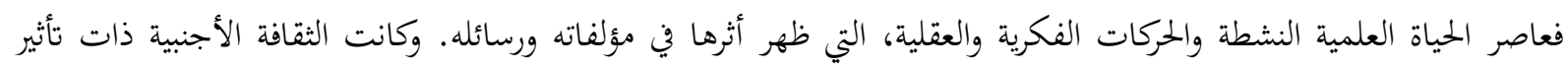

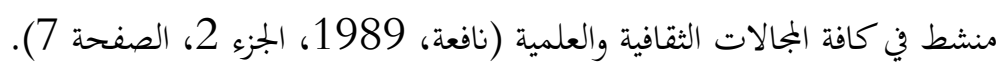

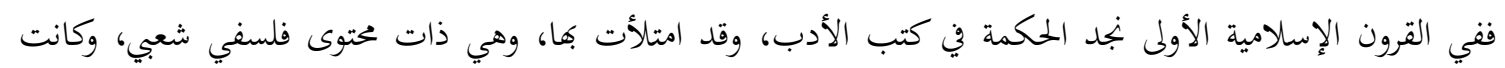

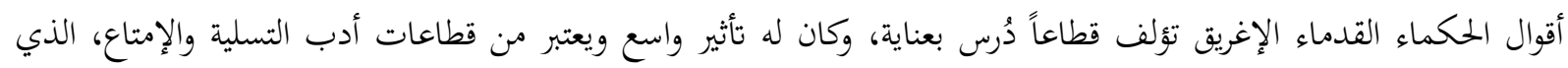

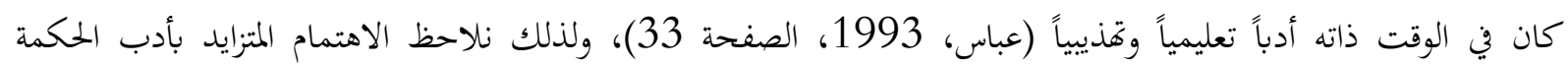
اليوناني، وكان قسم كبير من هذا الأدب قد ترجم في فترة مبكرة وكان أدباء هذا العصر يعيدوا إبرازه (عباس، 1993، 193، الصفحة

وكان لكبار علماء ومفكري وفلاسفة القرن الرابع الهجري / العاشر الميلادي، فضل في تلمذة التوحيدي بالفلسفة اليونانية

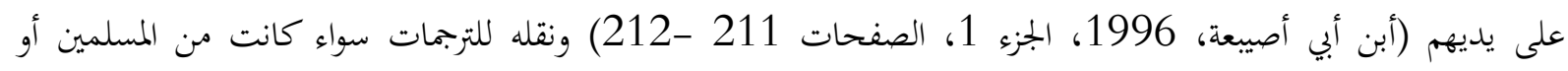

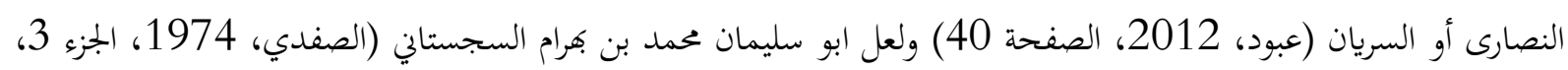

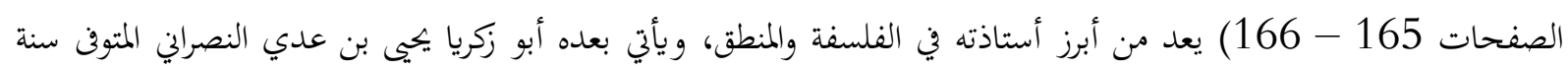

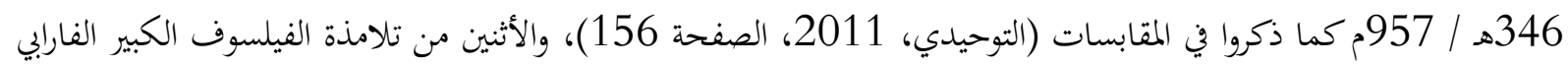

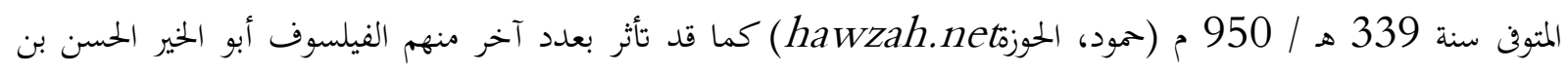

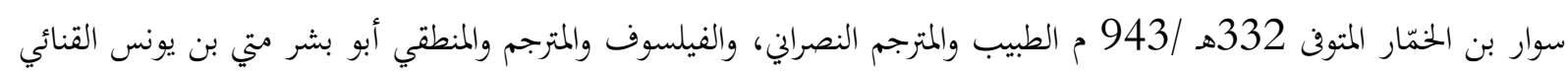

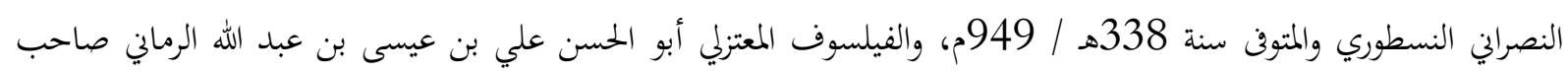

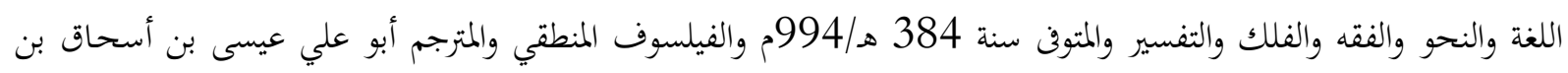

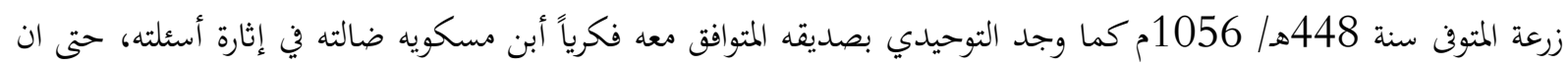

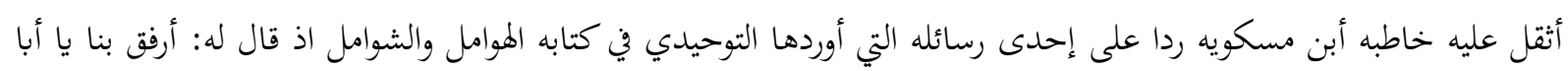

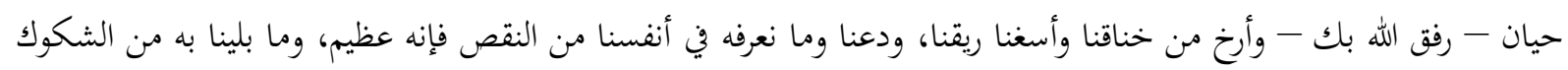

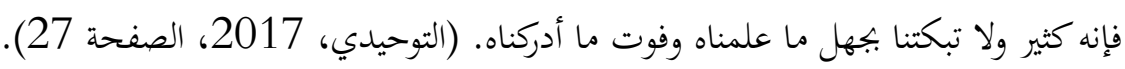

ثالثاً: الفلسفة اليونانية في مؤلفات التوحيدي

مما لا شك فيه إن الاتصال بين الثقافة العربية واليونانية كان قد بدأ بأولى حلقاته في العصر العباسي (أبو شهاب،

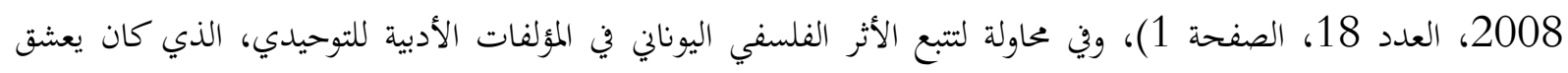

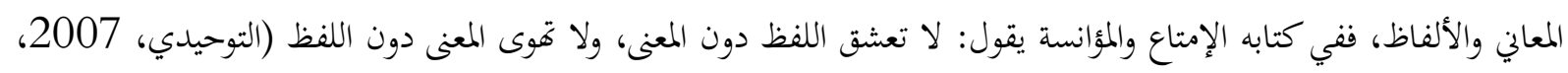

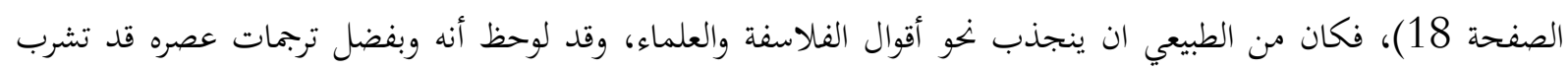
بالفلسفة اليونانية وحكمتها، لم يخفي انجذابه نخوها. 
كان إنشاء علاقات إنسانية متوازنة (حمود، الحوززhawzah.net) من أهم شواغل التوحيدي الفلسفية في كتبه ومؤلفاته

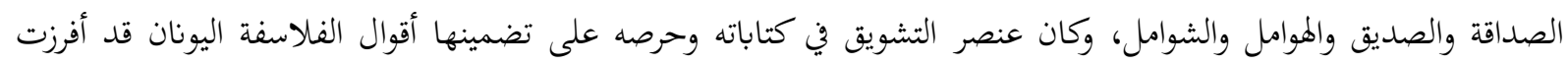
بسبب: ظهور شخصية المؤلف فيها بصورة واضحة بالإضافة إلى طبيعة المشاكل الخاصة التي تناولتها هذه الكتابات (نافعة،

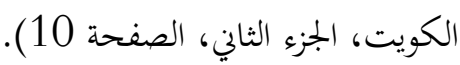

لقد وصف آدم مِتز التوحيدي بأنه أعظم كُتاب النثر العربي على الإطلاق! ومع ان كتاباته كانت غير منظمة ولا منسقة

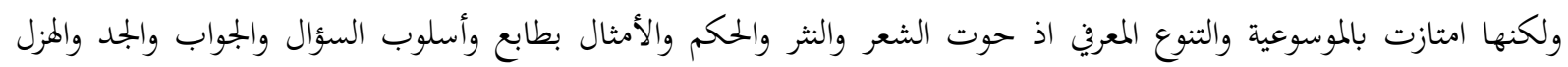
والنصيحة والموعظة، كما طغى حبه للفلسفة والتفلسف باستخدامه الألفاظ والتراكيب والاصطلاحات الفلسفية والمنطقية اليونانية

وأقوال لفلاسفة وعلماء وأدباء اليونان حتى أنه أود حكم لهوميروس ولمة (صاحب الإلياذة والأوديسة من القرن الثامن قبل الميلاد). فعلى سبيل المثال وردت في الليلة الثانية (2) والليلة السابعة عشر (17) من ليالي كتابه الإمتاع والمؤانسة الأربعون (40)

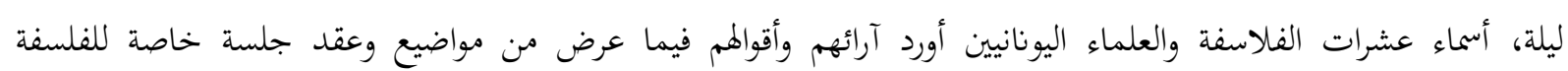

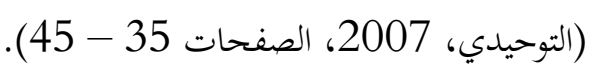

كما ذكر التوحيدي في كتابه الإمتاع والمؤانسة أخوان الصفا لأول مرة! ولم يكن قد ذكرهم أحد قبل التوحيدي ويبدو أنه

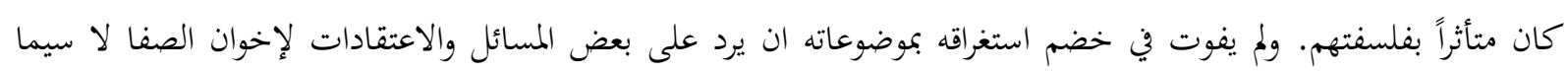

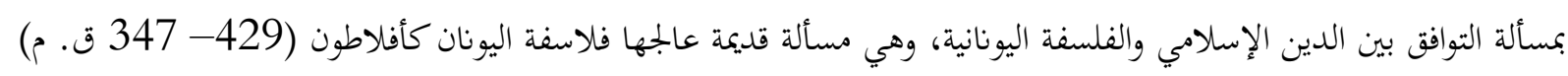

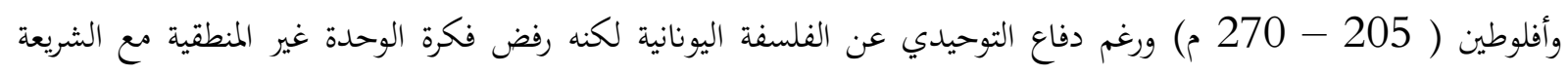

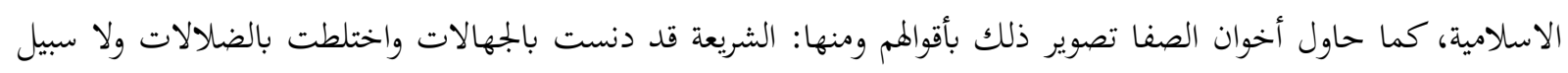

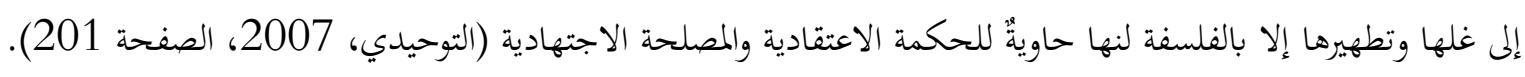
ويشير التوحيدي إلى أن أخوان الصفا قد ذهبوا بعيداً بقولم أنه متى انتظمت الفلسفة اليونانية والشريعة العربية فقد حصل

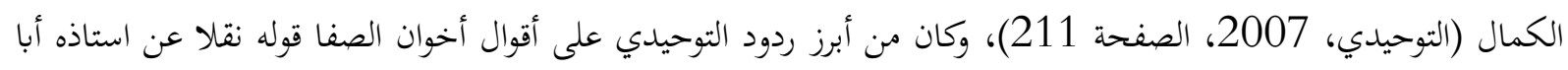

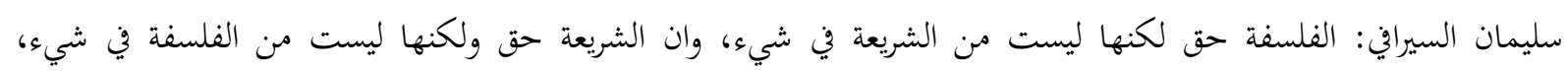
وصاحب الشريعة مبعوث، وصاحب الفلسفة مبعوث إليه وأحدهما خخصوص بالوحي، والآخر مخصوص ببحثيه، والأول مكفي

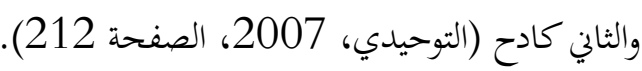

يمضي التوحيدي بمقالة طويلة برده على مسالة أخوان الصفا في التوفيق بين الدين والفلسفة فالتوحيدي ينفي أن يكون

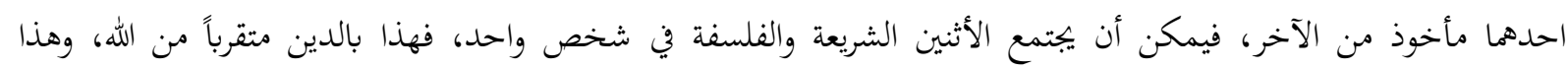

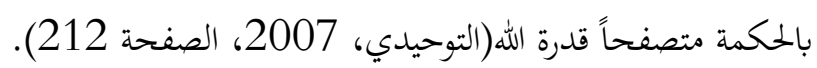

ويستند التوحيدي في ردوده على أخوان الصفا بآراء أستاذه أبي سليمان كقوله: من اراد أن يتفلسف فيجب عليه أن

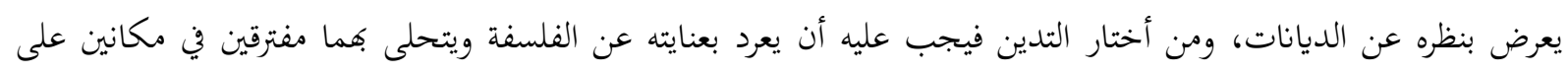

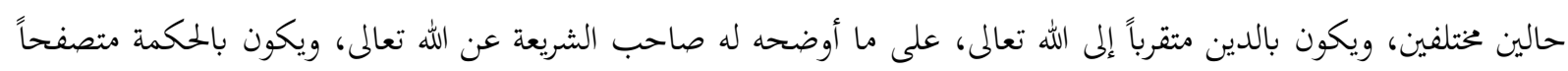

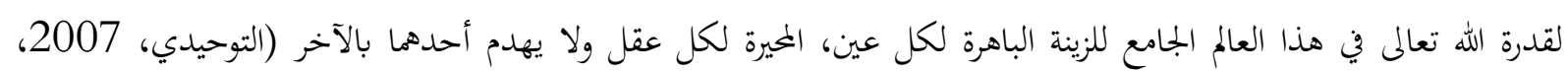
الصفحة 212).

لم يكن التوحيدي فيلسوفاً محضاً، ولم يكن صاحب نظرية في الفلسفة، لكنه عبر عن الأفكار الفلسفية المستسقاة من الكتب اليونانية المترجمة للغة العربية بقالب أدبي مبدع، فقد لخدص فيلم الأفكار الفلسفية هذه في كتابه المقابسات (التوحيدي،

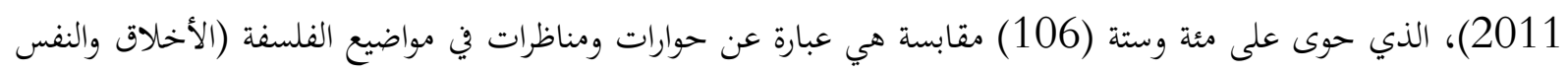


والطبيعة والإلميات) ناقشت بأسلوب أدبي قضايا فلسفية حتى إن البعض من الباحثين أعتبره كتابات أدبية بنكهة فلسفية ساهمت

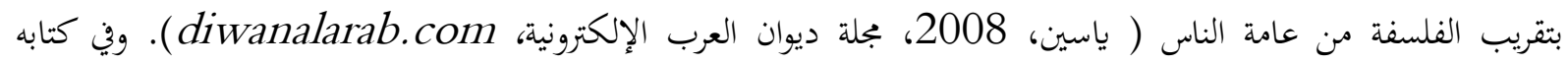
الإشارات الإلهية (التوحيدي، 1950) نجد التوحيدي يبث ابتهالاته بأسلوبه الفلسفي الفذ، مسجلاً في خضم ذلك العدئ العديد من الحوارات الفكرية والفلسفية.

رأى التوحيدي إن التباين أو الفرق بين الأدب العربي والفلسفة اليونانية لا يلغي إمكانية تعاوفما وإن النحو يزين المنطق

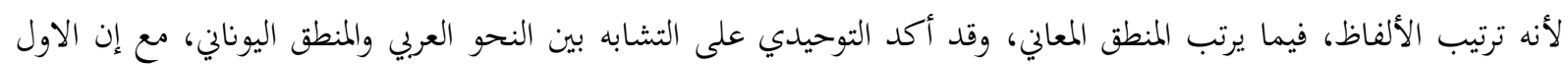

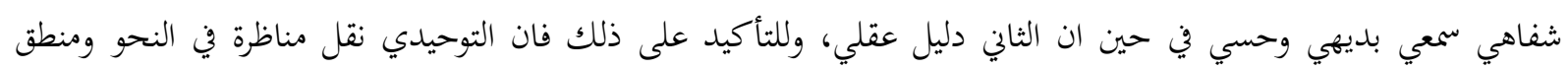

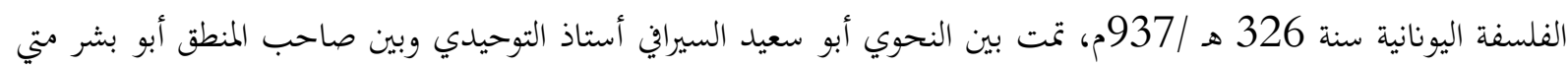

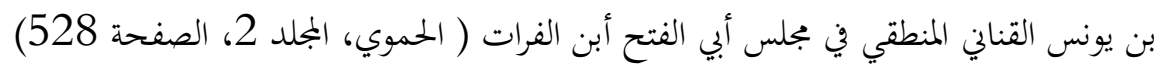
لقد بدت نزعة التوحيدي الفلسفية و تأثره بالفلسفة اليونانية وشغفه بها واضحة وبشكل جلي في كتابه الإمتاع والمؤانسة،

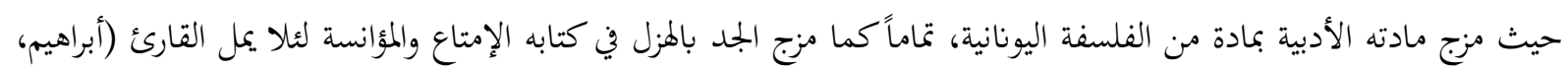

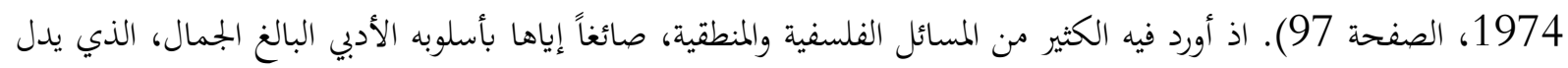

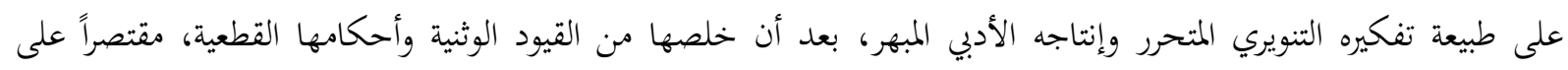
مناهجها الاستدلالية العقلية.

ولا ريب ان بداية تعرف التوحيدي على الفلسفة اليونانية في المرحلة الأولى تتبين من خلال عدم تحديد أصحاب بعض أقوال الفلاسفة اليونانيين واكتفائه بالقول: قال فيلسوف كما في كتابيه ال البصائر والذخائر والإمتاع والمؤانسة. أن العنصر التنويري في كتابات التوحيدي يظهر للعيان من جراء تعلقه بالفلسفة اليونانية وفهمه لوظيفة الفلسفة اليونانية

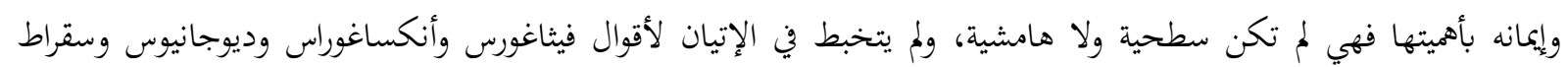
وافلاطون وارسطو.

ولذلك نجده لا يألو جهداً في الدفاع عنها والرد على من لم يفهم مقاصده منها وأول كلامه عنها، كما جاء في رسالته

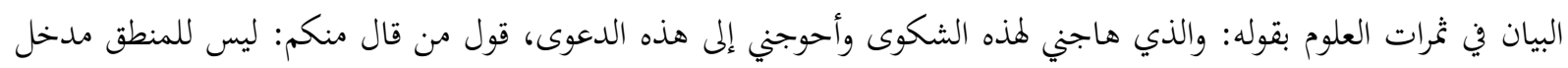

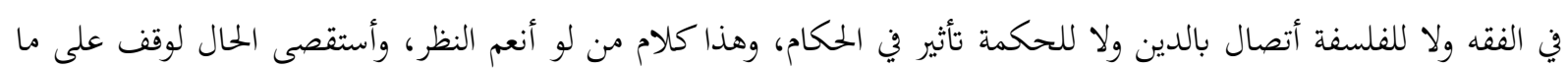

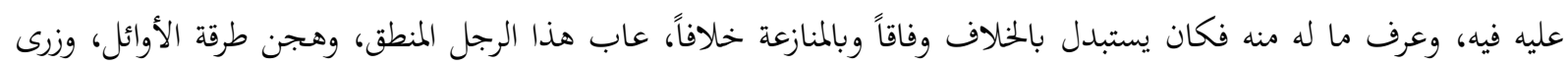

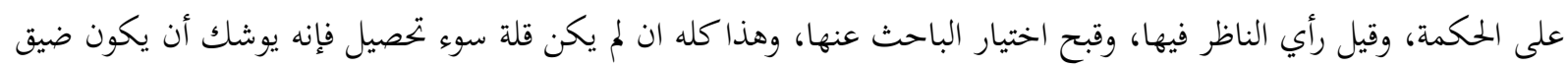

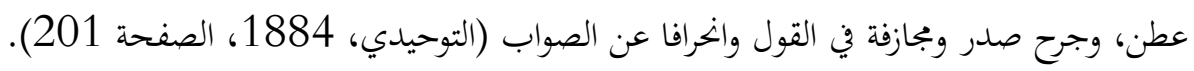
كما أورد التوحيدي في الإمتاع والمؤانسة مناظرة في سمة الفكر اليوناني وقيمته بخدمة الإنسانية ما بين كل من أبي بشر متي

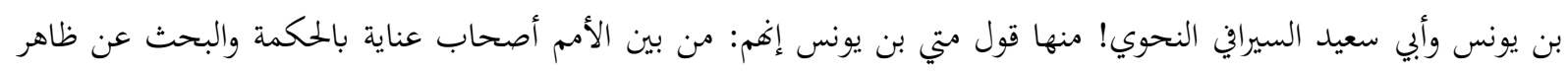

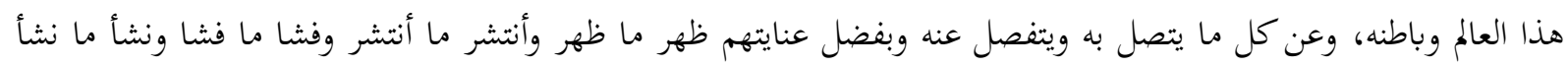

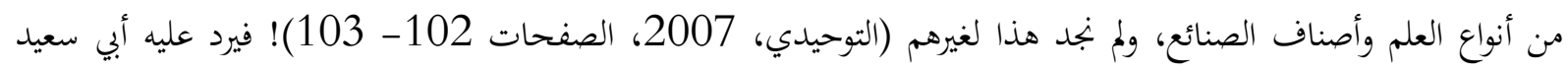

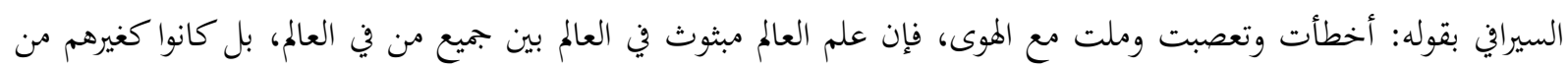
الأمم يصيبون في أشياء ويخطئون في أشياء، ويعلمون أشياء ويجهلون أشياء ويصدقون في أمور ويكذبون في أمور، ويحسنون في مني

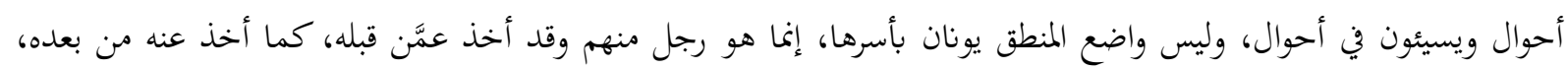

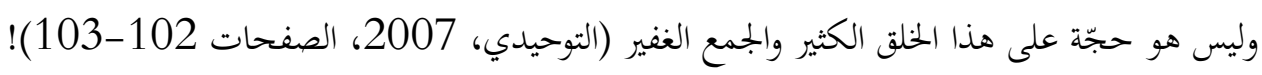


كانت الفلسفة والعلوم من بين أهم الروابط التي قاربت بين الثقافة الإسلامية التي باتت ثقافة عالمية في العصور الوسطى

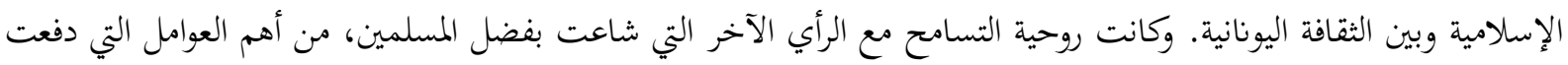

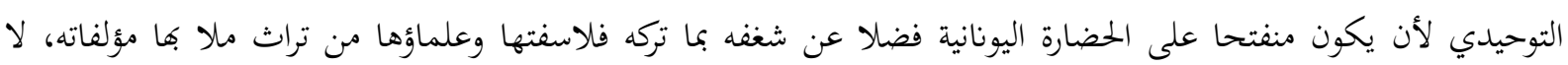

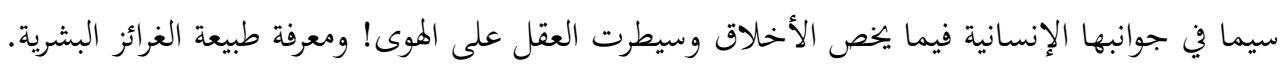

لقد أبدع التوحيدي في التعبير عن أفكار فلاسفة اليونان في القرن الرابع الهجري / العاشر الميلادي وصارت كتبه سجلات

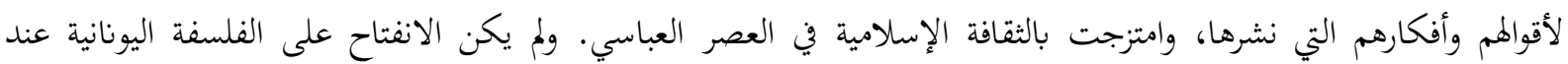
التوحيدي بالخاصية الذاتية، بقدر ما كانت روحية مشتركة بين عدد من أدباء عصره، وقد أبدى التهات التوحيدي أعجاباً شديداً

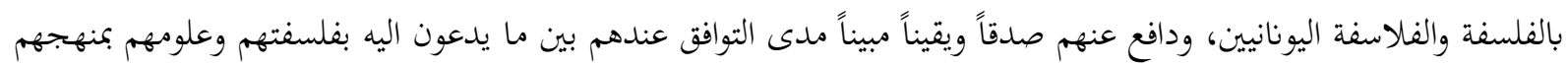
الأخلاقي والعقلاني، وبين ما كانوا ملتزمين به ويطبقونه بسلوكهم على أرض الواقع فعلاً وعملاًا! 
قائمة المصادر والمراجع:

أولا: المصادر

أبن أبي أصيبعة موفق الدين أبي العباس أممد بن القاسم بن خليفة بن يونس السعدي الخزرجي( ت668 هـ / 1270 م). (1996).

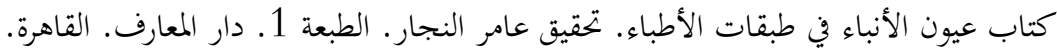

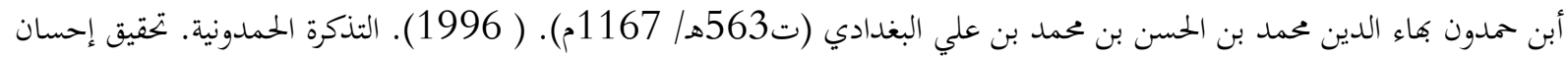

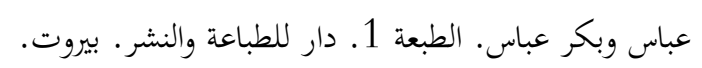

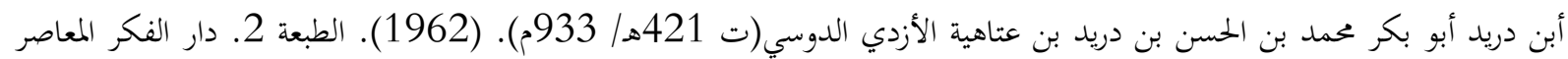

عن دائرة المعارف العثمانية.

أبن النديم أبي الفرج حممد بن إسحاق (ت 380 هـ/ 990م). (2010). الفهرست. تحقيق يوسف علي الطويل. الطبعة 3، دار الكتب

$$
\text { العلمية. بيروت. }
$$

أبن خلكان أبو العباس شمس الدين أممد بن محمد بن إبراهيم بن أبي بكر الشافعي (ت 681 هـ / 1282م). ( 1998). وفيات

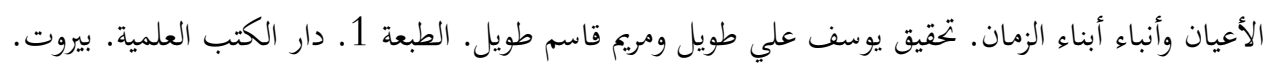

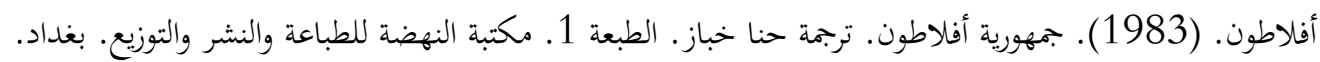

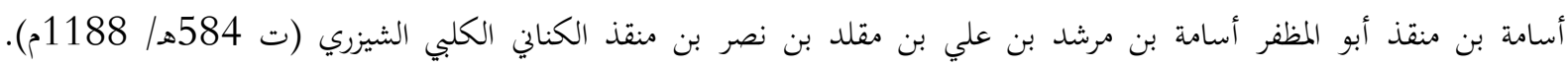
(1987) لباب الآداب. تحقيق أممد عممد شاكر . منشورات مكتبة السنة. الدار السلفية لنشر العلم. القاهرة.

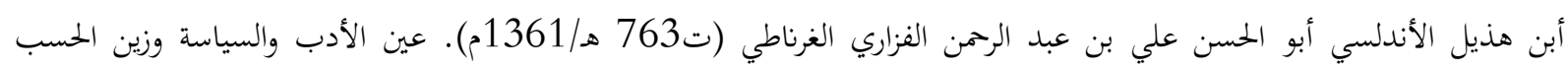

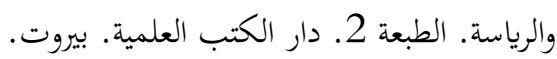

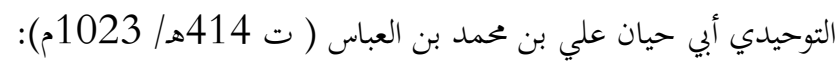

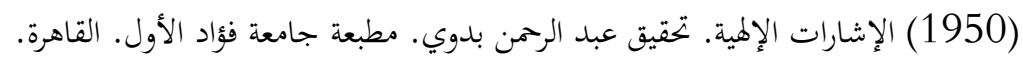

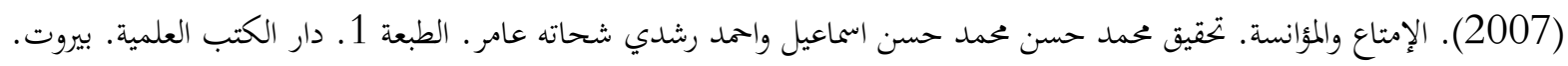

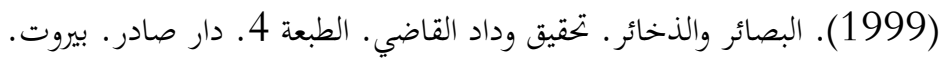

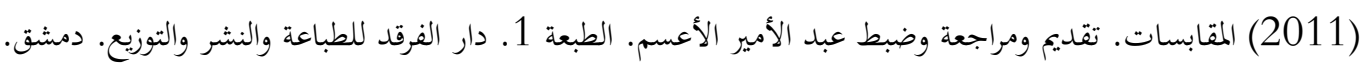

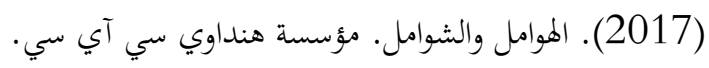

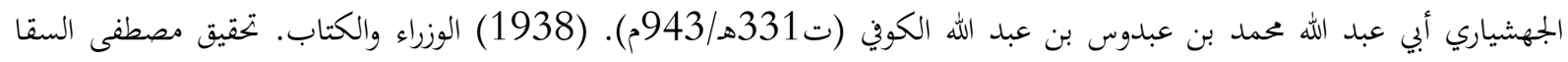
وإبراهيم الأبياري وعبد الحفيظ شبلبي. الطبعة 1. مطبعة البابي الحلبي وأولاده. القاهرة.

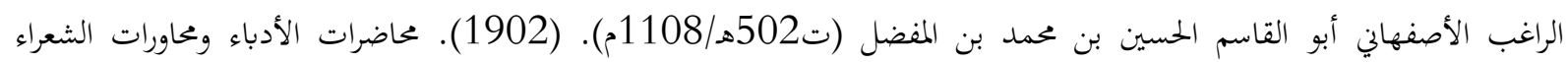

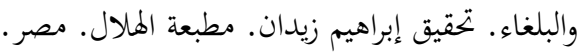

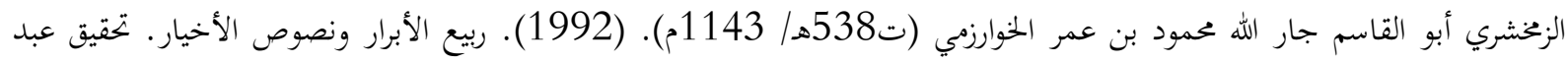

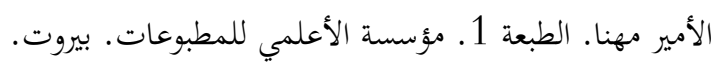

الصفدي صلاح الدين خليل بن أيبك (ت 764هـ 1363م). ( 1974). الوافي بالوفيات. تحقيق س. ديدرينغ،.فرانز شثاينر. فيسنبادن.

ياقوت الحموي أبو عبد الله ياقوت بن عبد الله الرومي (ت 626هـ/ 1228م). (1991). معجم الأدباء أو إرشاد الأريب إلى معرفة الأديب. الطبعة 1. دار الزهراء. دار الكتب العلمية بيروت.

ثانياً: المراجع

زكريا إبراهيم. أبو حيان التوحيدي. المؤسسة المصرية العامة. مطبعة مصر. القاهرة. معمود أبراهيم. (1974). كتاب أبو حيان التوحيدي في قضايا الإنسان. الطبعة 1، الدار المتحدة للنشر. بيروت. 
رامي أبو شهاب. (حزيران / 2008). الثقافة اليونانية وأثرها في الأدب العربي. مجلة الكلمة. العدد 18. عبد الرمن بدوي. (1967). دور العرب في تكوين الفكر الأوربي. الطبعة 2. القاهرة.

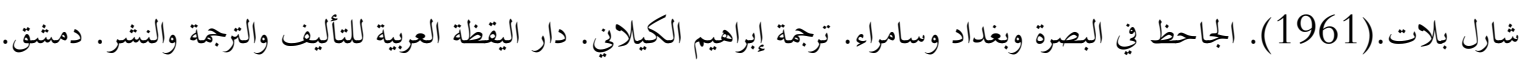

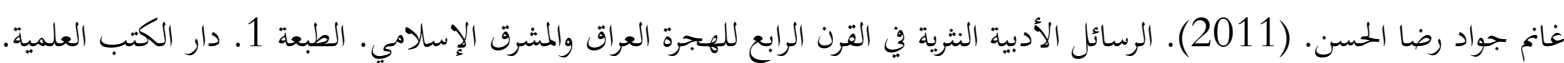

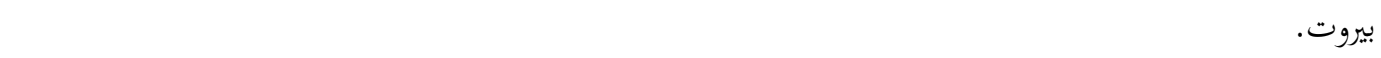

ماجدة حمود. صورة الآخر في التراث العربي صورة الآخر لدى أبي حيان التوحيدي. مجلة آفاق الحضارة الإسلامية. موقع الحوزة الإسلامي hawzah.net.

فدوى محمد سليمان الخوالدة. ثقافة الجاحظ الأدبية والنقدية واللغوية من كتاباته. رسالة ماجستير غير منشورة. جامعة آل البيت. كلية الآداب والعلوم الإنسانية. قسم اللغة العربية وآداهما. الأردن.

تركي بن الحسن الدهماني (2021). أخبار الجاحظ. الطبعة 1. أمواج للطباعة والنشر والتوزيع. عمان. الأنسان.

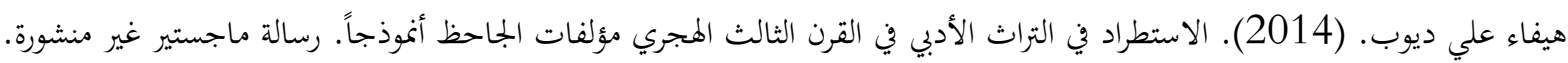
جامعة تشرين. كلية الآداب والعلوم الإنسانية. قسم اللغة العربية. اللاذقية.

عبد اللطيف الزكوي. (2017/1/22). الأدب الفلسفي. موقع جبهة النضال الشعبي الفلسطيني. أيمن فؤاد سيد.(1/ 7 / 1995). أبو حيان التوحيدي ومؤلفاته المخطوطة والمطبوعة. مجلة فصول. الهيئة المصرية العامة للكتابة. العدد 3.

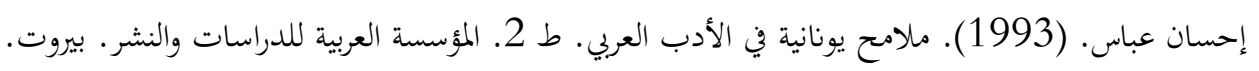
أحمد عبد المادي.(1997) . أبو حيان التوحيدي فيلسوف الأدباء وأديب الفلاسفة. دار الثقافة للنشر والتوزيع. القاهرة. مارون عبود.( 2012). أدب العرب. مؤسسة هنداوي للتعليم والثقافة. القاهرة. عبد القادر العربي. (2014). بلاغة الخطاب وإبلاغية التأويل في محاورات أبي حيان التوحيدي. حوليات الآداب واللغات جامعة المابلات المسيلة.

$$
\text { الجزائر. العدد } 344 .
$$

$$
\text { كامل محمد محمد عويظة. الجاحظ الأديب الفيلسوف. دار الكتب العلمية. بيروت. }
$$
بيار ماشيري. (2009). بم يفكر الأدب؟ تطبيقات في الفلسفة الأدبية. تربمة جوزيف شريم. ط 1 1. المنظمة العربية للترجمة. مركز دراسات

$$
\text { الوحدة الربية. بيروت. }
$$

آدم متز . (1957). الحضارة الإسلامية. ترجمة محمد عبد الهادي أبو ريدة. ط 3. مطبعة لجنة التأليف والترجمة والنشر. القاهرة.

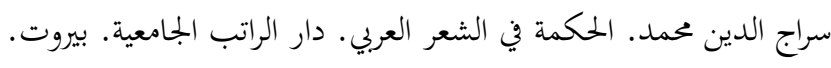

$$
\begin{aligned}
& \text { حسن نافعة وكليفورد بوزورث. (1989). تراث الإسلام، عالم المعرفة. الكويت. }
\end{aligned}
$$

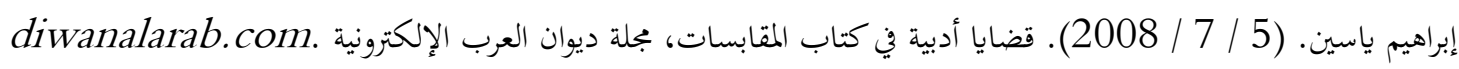

